\title{
Understanding and Forecasting Zonda Wind (Andean Foehn) in Argentina: A Review
}

\author{
Federico A. Norte \\ Instituto Argentino de Nivología, Glaciología y Ciencias Ambientales (IANIGLA), CCT-CONICET, Mendoza, \\ Argentina \\ Email: nortefederico@hotmail.com, fnorte@prmarg.org
}

Received 1 April 2015; accepted 10 May 2015; published 15 May 2015

Copyright (C) 2015 by author and Scientific Research Publishing Inc.

This work is licensed under the Creative Commons Attribution International License (CC BY).

http://creativecommons.org/licenses/by/4.0/

(c) (i) Open Access

\section{Abstract}

This paper focuses on the "state of the art" research of the Argentinian zonda wind at the beginning of 2015. Zonda (similar to foehn) is a strong, warm, very dry wind associated with adiabatic compression upon descending the eastern slopes of the Andes Cordillera in western central Argentina. Particularly, hourly surface meteorological information obtained from the Argentine National Weather Service (Servicio Meteorológico Nacional, SMN) from Mendoza Aero (32 ${ }^{\circ} 50^{\prime}$, $\left.68^{\circ} 47^{\prime} \mathrm{W}, 704 \mathrm{~m} \mathrm{ASL}\right)$ and San Juan Aero ( $31^{\circ} 34^{\prime} \mathrm{S}, 68^{\circ} 25^{\prime} \mathrm{W}, 598 \mathrm{~m}$ ASL) airport meteorological stations was used. The paper contains a history of zonda research mentioning the principal papers since the 1950s, the characteristics of zonda wind (conceptual model, a classic event, intensities categories) and examples of non-classical episodes. Also zonda dynamics, zonda climatology and forecasting problems are considered. A probabilistic method and the model forecast that are running in operative way are commented. Also the climate impact, air quality and damages caused are mentioned. There has been substantial progress in the understanding of this kind of complex wind during the last years, especially since the last decade, accelerated using different models. This paper has highlighted some of these advances by synthesizing some of the major findings. The probabilistic prediction method developed in the 1980s is still very useful to predict zonda in the cities of San Juan and Mendoza. This as well as the new available tools, such as the eta/PRM and GEM models running operatively (continuously) at PRM (Mendoza Regional Meteorology Program), offered the community the possibility to generate an Early Warning System to warn the population particularly in its severe manifestations. The answer to questions regarding time of onset of the event, place where it will occur first, duration, intensity and offset still poses a great challenge for researchers and forecasters in the region.

\section{Keywords}

Zonda, State of the Art, Climatology, Forecast, Damages, Societal Impact 


\section{Introduction}

This paper focuses on the "state-of-the-art" research of the Argentinian zonda wind at the beginning of 2015. Zonda is a strong, warm, very dry wind associated with adiabatic compression upon descending the eastern slopes of the Andes in western central Argentina, with a higher frequency in the winter and spring seasons. Zonda has specific features (such as remarkable spatial and temporal variability), and complex behavior of associated meteorological parameters (such as temperature, relative humidity, surface pressure, and wind intensity). In populated regions, it produces a range of damage according to the intensity of wind gusts (e.g., blowing off roofs, felling trees and high-voltage electricity lines, and shutting down power supply and communication lines). In addition, it favors the ignition and propagation of fires and causes damage to crops due to the strong gusts, sudden dryness and high temperatures, and it may also be responsible for premature fruit flowering. At high altitudes in the mountains, its occurrence accelerates snow melting and evaporation, modifying the snow pack depth, contributing to avalanches, and influencing the hydrological cycle [1] [2].

Initial investigations into this kind of wind focused on the Alpine region, where it is known as the "Foehn". This term became the generic name for all descending, warm, dry winds [3] whose features and effects depend on topography, its interaction with the atmospheric flux, and the particular meteorological conditions [1] [2]. Such winds have different names depending on where they blow [1] [4]: “Chinook” in the USA and Canada east of the Rocky Mountains [5], “Canterbury-northwestern” in New Zealand [6], "berg wind” in South Africa [7], "afganet” in Central Asia, “ibe” in western China [3], "halny wiatr” in Poland and Slovakia [3], and "austru” in western Romania [3].

Several papers about foehn exist but the orography of the European Alpine area is quite different from that in the South American Andes where zonda winds blow. The central-western zone of Argentina, named Cuyo, includes the provinces of Mendoza, San Juan and San Luis (Figure 1). The zonda mostly affects western Mendoza and San Juan areas. The largest population is found in Mendoza city ( $32^{\circ} 51^{\prime} \mathrm{S}, 68^{\circ} 49^{\prime} \mathrm{W}, 754 \mathrm{~m}$ ASL) and in San Juan city $\left(31^{\circ} 36^{\prime} \mathrm{S}, 68^{\circ} 33^{\prime} \mathrm{W}, 630 \mathrm{~m}\right.$ ASL) with 1.5 million inhabitants. The Andes run meridionally from $55^{\circ} \mathrm{S}$ to $10^{\circ} \mathrm{N}$ with a mean width of $250 \mathrm{~km}$; height varies with latitude.

At the latitude of the Cuyo region the Andes constitute a barrier to the western flow, with a mean altitude of $4500 \mathrm{~m}$ ASL and a maximum of $6959 \mathrm{~m}$ ASL over mount Aconcagua [2]. On the other hand, the Alps, which run latitudinally, are lower mountains located at a higher latitude than the more frequent zonda wind area of occurrence. Therefore, the general circulation systems are different.

By gathering and summarizing all the research done up to the moment on the topic of zonda wind in Argentina, this work ultimately aims to serve as a tool for current and future generations of researchers and also as a ba sis for regional and national early warning systems.
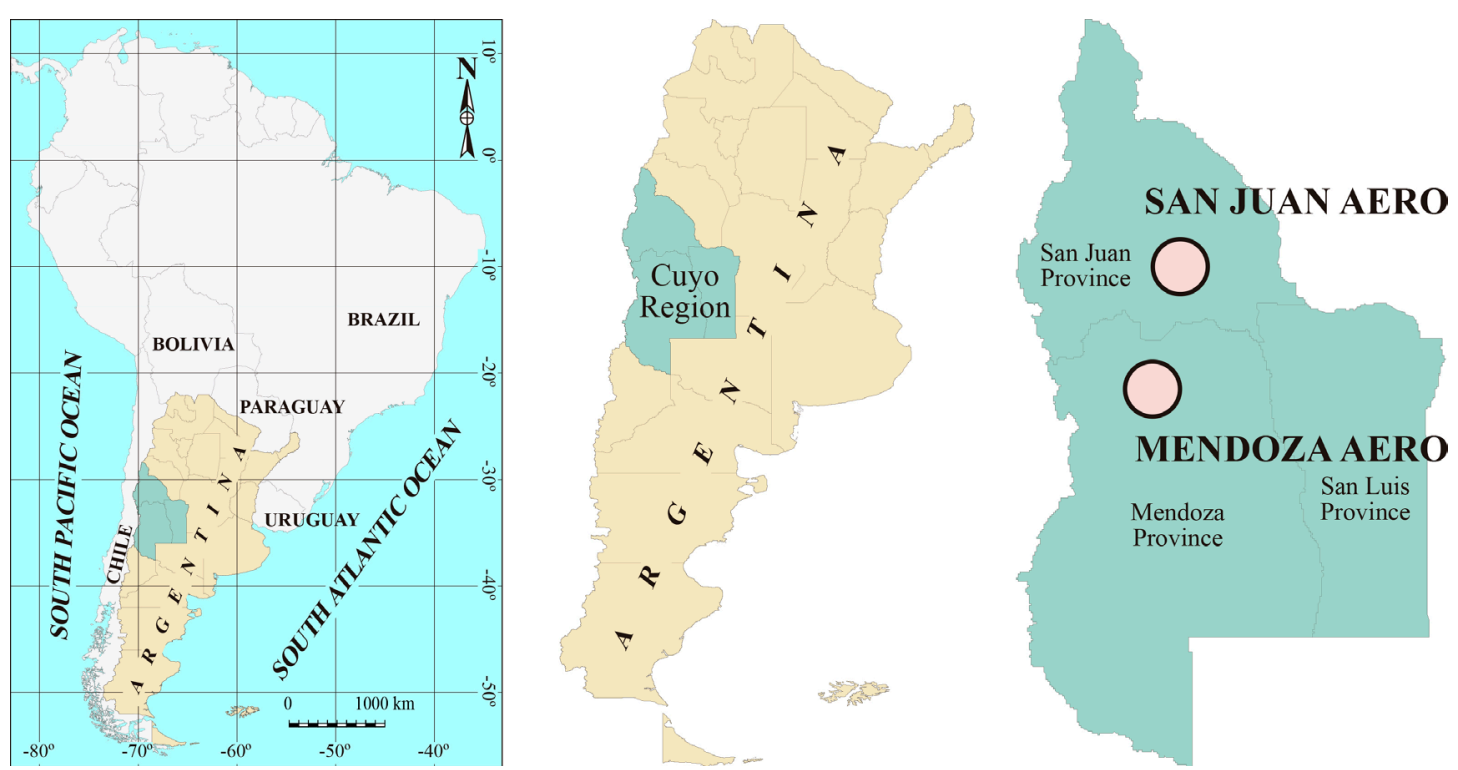

Figure 1. Location of Argentina and Cuyo region in South America. 
The structure of this paper is as follows: Section 2 describes the data and methodology; Section 3 presents a history of zonda research monitoring the principal papers since the 1950s; Section 4 contains the characteristics of zonda wind (including a conceptual model, the analysis of a classic event, intensities categories and two examples of non-classic episodes); Section 5 describes some aspects of zonda dynamics (like lee-side motion, interaction with cold-pool, pulsating zonda and orographic waves); Section 6 analyzes zonda climatology; Section 7 considers forecasting problems (a probabilistic method and the model forecast that are running in operative way are commented); the societal impact of zonda is mentioned in Section 8 (including climate impact, air quality, zonda wind damages and biometeorological effects); and, finally, the discussion and conclusions about this zonda review are presented in Section 9.

This work (that is, the summary of the zonda research in Argentina, especially in Cuyo areas of this country) is of great importance because it presents the most current and comprehensive information about this phenomenon, and it will constitute a valuable tool for new researchers and decision makers.

\section{Data and Methodology}

The information used in almost all the papers about zonda wind published since the 1950s was obtained from the Argentine National Weather Service (Servicio Meteorológico Nacional, SMN). Particularly, hourly surface meteorological information from Mendoza Aero $\left(32^{\circ} 50^{\prime} \mathrm{S}, 68^{\circ} 47^{\prime} \mathrm{W}, 704 \mathrm{~m}\right.$ ASL) and San Juan Aero (31 $34^{\prime} \mathrm{S}$, $68^{\circ} 25^{\prime} \mathrm{W}, 598 \mathrm{~m} \mathrm{ASL}$ ) airport meteorological stations was used. Other stations belonging to the SMN and other regional institutions were also considered in many papers. Zonal time used in Argentina is equivalent to 3 hours before UTC time (GMT-3), and midday in Mendoza and San Juan is about 13:40 local time.

Rawinsonde information from Mendoza aero has been relevant, too, but during winter there are no upper-air sounding data in this airport. Therefore, to analyze vertical atmospheric conditions and their evolution, historical upper-air data from the National Oceanic and Air Administration (NOAA) Air Resources Laboratory (ARL) Real-Time Environmental Applications and Display System (READY) were used. Re-analysis data from the National Center of Environmental Prediction-National Center for Atmospheric Research (NCEP-NCAR) [8] were used to analyze the synoptic situation for the different events studied in the papers.

Zonda wind episodes have been detected using the methodology used by Norte [1] and recently by Otero \& Norte [9]. Several models have been used in the past trying to understand the physical processes of the zonda wind in order to perform diagnostic studies and to forecast it. In Seluchi et al. [10] and Norte et al. [11] Eta/ CPTEC (Centro de Previsão de Tempo e Estudos Climáticos do Brasil, or Brazilian Center for Weather Forecast and Climate Studies) model has been applied. Its specifications can be consulted in Messinger [4] and Seluchi et al. [10].

The Eta/PRM (Programa Regional de Meteorología, or Regional Meteorology Program of Argentina) model is a regionalized version of the Eta/CPTEC model adapted to the central-western region of Argentina. It has been running in an operative form in the PRM of CONICET (National Research Council) in Mendoza, Argentina, since 2006. It has $15 \mathrm{~km}$ of horizontal resolution and 38 vertical levels, covering the central region of Chile and the western and central areas of Argentina, including the Andes [11].

The BRAMS model (Brazilian Regional Atmospheric Modeling System) has been used to analyze a very severe zonda wind episode [2]. The BRAMS model is a modified version of the Regional Atmospheric Modeling System (RAMS). A comprehensive description of RAMS can be found in Cotton et al. [12] and in Ulke [13]. It is a multipurpose numerical prediction model designed to simulate atmospheric circulations on several scales. The physical processes, such as radiation, deep and shallow convection, turbulence, cloud microphysics, and surface-air exchanges are represented by a complex set of packages. BRAMS and RAMS models have been applied to study and analyze several phenomena in Argentina and South America, formerly in Brazil and later in Argentina [2].

The Global Environmental Model (GEM) is a fully non-hydrostatic global model with a horizontal variable grid, which has been used to forecast zonda winds. The horizontal grid-spacing goes from 1.5 degrees to 0.013 degrees in the area of interest. Figure 2 shows the stretched grid section (centered in Mendoza province) of the global domain and the topography used by the GEM model. The vertical levels, turbulent boundary, layer processes, cumulus convection, long and short wave radiation and microphysical processes are parameterized according to the RPN Physics library (Recherche en Prévision Numérique, Dorval, Quebec, Canada). In the vertical coordinate, 58 stretched levels are used with a fine grid spacing structure near the planetary boundary layer and coarser spacing in the upper atmosphere. 


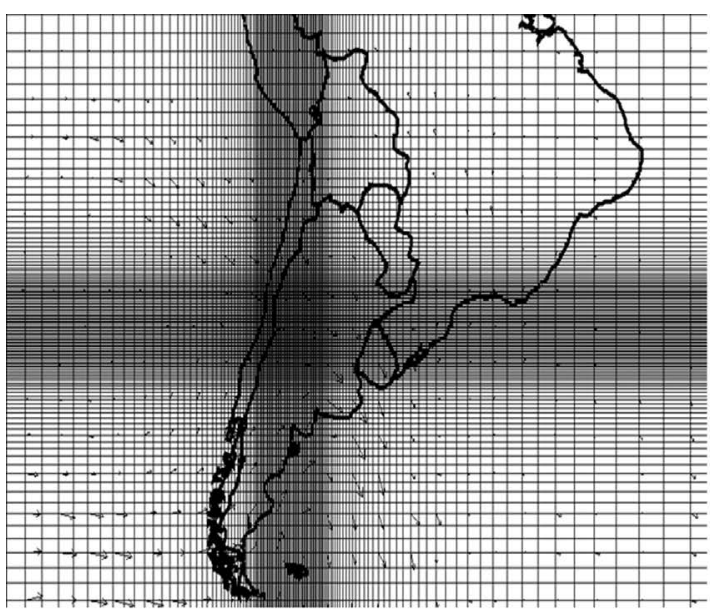

(a)

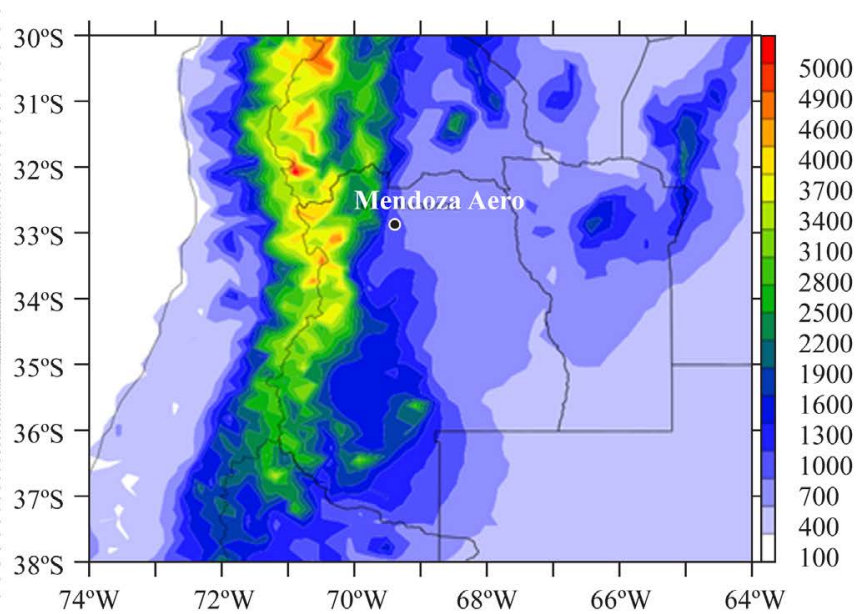

(b)

Figure 2. (a) Stretched grid section (centered at Mendoza province) of the global domain; and (b) the topography used by GEM model.

The Weather Research and Forecasting model (WRF) is another state-of-the-art model whose setting is specified in Figure 3. In the vertical axis, 38 levels are used with a stretched structure similar to that used by GEM. Three nested domains are used with a corresponding grid spacing of $36 \mathrm{~km}$ (domain 1), $12 \mathrm{~km}$ (domain 2 ), and 4 km (domain 3) (Figure 4). WRF and GEM models are analyzed with NCEP FNL (Final Operational Global analysis data on $1.0 \times 1.0$ degree grid).

The methodology applied to achieve the goal of this paper was to follow a rather similar scheme to that developed by Richner \& Hechler [14], trying to find differences and similarities in zonda wind research conducted in western areas of Argentina close to the Andes with respect to the foehn in Europe.

\section{History of Zonda Research}

The zonda background in Argentina is specifically treated in some works, while in others, although the central subject is different, zonda wind is also mentioned.

Georgii [15] shows the importance of the atmospheric pressure double daily wave in Mendoza, which influences the beginning of zonda (and also in other phenomena such as the interruption of cold air and summer convective storms). Some time later, Georgii [16] offered detailed information about zonda with the data available at that time (from mountain meteorological stations which do not exist presently and from measurements taken from planes).

Rolón de los Santos \& Afonso [17] analyze zonda events in the cities of Mendoza and San Juan for the 1967-1976 period and mention the statistic and synoptic aspects of those events.

Lichtenstein [18] studied the Northwest Argentine Low (NAL) and its relationship with some regional meteorological phenomena in western Argentina. He found that NAL displacement to higher latitudes and its deepening are related to the adiabatic descent associated with a zonda wind event.

Norte [1] made an exhaustive description of the typical climatic, synoptic and thermodynamic conditions using data from aerological and surface stations for winter during the 1974-1983 period. That work distinguished between high zonda, which occurs when the wind reaches the stations located on the eastern slopes of the mountains, and surface zonda, which is detected over the plains east of the Andes, typically in the proximity of Mendoza and San Juan cities. The characteristics of some severe cases were also analyzed according to data from Mendoza Aero taken on August $6^{\text {th }}$, 1980, September $13^{\text {th }}, 1982$, and May $27^{\text {th }}, 1986$. These events were good representatives of this kind of situations.

Seluchi et al. [10] undertook a complete description of three distinct zonda categories that represent three classical episodes: severe surface zonda, moderate surface zonda, and high zonda wind. A severe zonda on August $5^{\text {th }}$, 1999, was analyzed thoroughly. It began near midday, which coincided with the climatological timing for the severe episode features [1] and had the typical features of a severe zonda wind episode. The Eta/Centro 


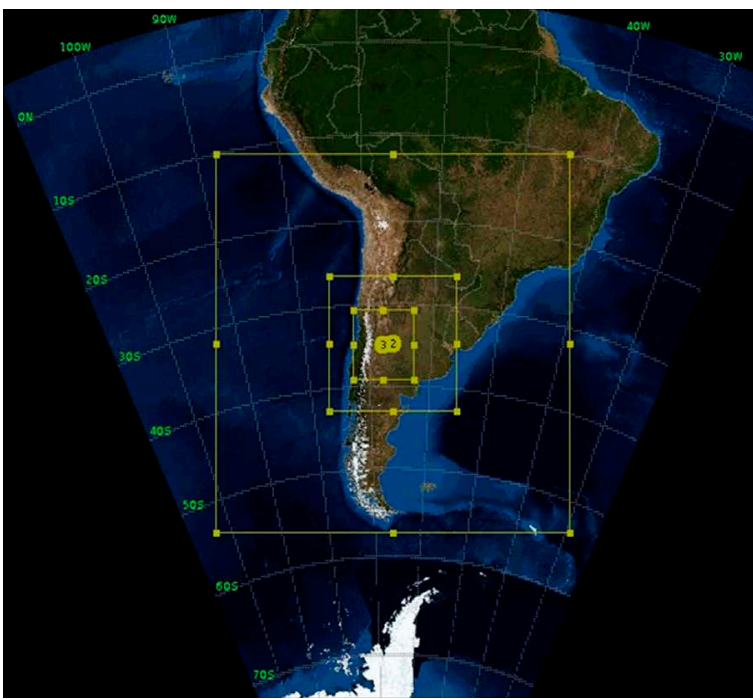

\begin{tabular}{ll}
\hline $\begin{array}{c}\text { Parameterized } \\
\text { Physical Process }\end{array}$ & \multicolumn{1}{c}{ Scheme } \\
\hline Boundary layer & YSU \\
Cumulus convection & Kain-Fritsch (new ETA) \\
Long-Wave Radiation & RRTM \\
Long-Wave Radiation & Dudhia \\
Microphysics & WSM 3-class simple ice scheme \\
\hline
\end{tabular}

Figure 3. WRF model setting specification.

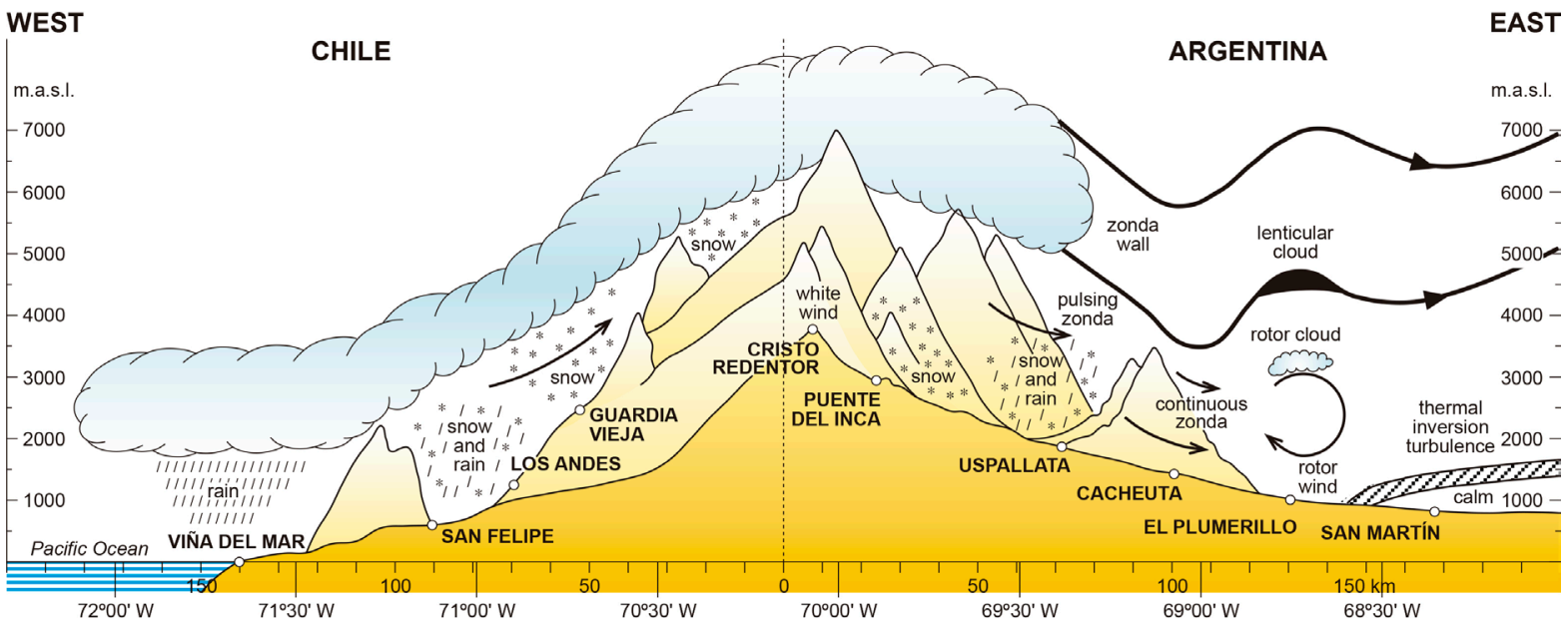

Figure 4. Typical scheme or conceptual model of zonda wind at Mendoza Aero latitude.

de Previsão de Tempo e Estudos Climáticos (CPTEC) operational regional NWP model was evaluated for the first time as a potential forecasting tool and was employed to explore the three-dimensional structure of the phenomenon.

Norte et al. [11] analyzed the meteorological conditions that caused the occurrence of an intense heat wave over subtropical South America, with temperatures higher than $40^{\circ} \mathrm{C}$ immediately to the east of the Andes, during the last week of January 2003. On January $30^{\text {th }}$ the maximum temperature reached $44.4^{\circ} \mathrm{C}$ in Mendoza aero (the highest of a whole record). The strong temperature increase was caused by adiabatic warming (subsidence) as well as by the net positive surface heat flux, especially to the east of the Andes, and the presence of forced orographic subsidence (zonda wind) is evident from observations and numerical simulations.

Norte et al. [2] studied a very severe zonda wind event occurring on July $11^{\text {th }}$, 2006, that reached and maintained the higher category FNZ4 for several hours. The study evaluated the ability of the BRAMS model to represent the features of this extreme episode and explored if it could be used to predict this kind of zonda events with satisfactory results. In Viale \& Norte [19] a heavy winter storm is studied exhaustively and zonda wind is analyzed in the leeward side of the Andes.

Chiconi [20] established a set of representative cramping episodes in horses to investigate if they are influenced by weather. The specific objective of this work was to analyze the influence of zonda wind in height and/or surface, the change in atmospheric pressure, and cold fronts coming to the region on the occurrence of 
episodes of colic in horses.

Palese \& Cogliati [21] recently analyzed Neuquen Aero ( $38^{\circ} 57^{\prime} \mathrm{S}, 68^{\circ} 08^{\prime} \mathrm{W}, 272 \mathrm{~m}$ ASL) meteorological time series to identify zonda wind cases in this Argentinean city of North Patagonia. They used the following criteria: an increase of $5.0^{\circ} \mathrm{C}$ or more in air temperature, a decrease of $7.0^{\circ} \mathrm{C}$ or more in dew point temperature in one hour wind blowing from western or northern direction, lenticular altocumulus clouds, and eventually, dust storms and strong winds at $700 \mathrm{hPa}$ level in the Andes mountain range at Neuquen city latitude. With these features, fifty cases were detected which can be confirmed as zonda wind in the analyzed series between 1981 and 2012. Sixty percent of the cases detected belonged to FNZ1 categories.

Otero \& Norte [9] intended to evaluate possible methods of objective classification of zonda wind events and update the statistics of this phenomenon in the city of San Juan. All methods were able to identify many of the zonda wind events in San Juan. Next, these methods were compared with subjective classification methods. The diurnal and monthly cycle, onset, offset and average duration were compared. After comparing the methods, those events subjectively classified were taken, and a new classification was made according to the maximum wind speed. A weather description was made, and the differences were discussed with respect to the new classification, the daily and annual cycle, duration and onset. Then, the percentage frequency of wind directions for different zonda wind intensities was described. Finally, the percentage distribution of the gusts and wind speed for the entire zonda wind data was analyzed.

In Otero et al. [22] a probability index of surface zonda wind occurrence was obtained by using the principal component analysis (PCA) evaluating its ability to identify zonda wind associated patterns. An entry matrix was built with the temperature and dew point temperature anomalies for the standard levels between 850 and 300 $\mathrm{hPa}$. The analysis yielded six significant components and explained $94 \%$ of the variance. Thus, representative patterns of favorable weather conditions for the development of the phenomenon were obtained.

The zonda/non-zonda indicator can be estimated by a logistic multiple regression dependent to the component loadings, calculated from the $T$ and $T d$ profiles depending on the climatological features of the region. The highest correlations between the CP and index values and non-zonda/zonda were obtained for components 2,4 and 5. The index showed an efficiency of 74.7\%.

The aim of the paper by Yechuchen et al. [23] was to study the vertical structure of the atmosphere at different radiosonde stations in the southern tip of South America during zonda events in the Andean region. Vertical profiles for temperature $T$, dew point $T d$, and the difference $T$ - $T d$ were composed at all mandatory levels between 850 and $10 \mathrm{hPa}$ for dates when zonda was registered at Mendoza Aero. At each location, the profiles were compared with the long-term climatology ones, and for each level the difference between them was tested statistically. In general, there is a substantial modification in humidity conditions at various levels of the troposphere not only in the region where the zonda blows but also to the east of it, in the central region of Argentina; such conditions are also seen west of the Andes in Chile. Furthermore, the vertical profiles show that the position of the tropopause for zonda events differs from the climatology ones at some of the stations analyzed.

\section{Characteristics of Zonda Wind}

\subsection{Conceptual Model}

Like in the Alps, the conceptual model of zonda wind in the South American Andes is quite similar to the "textbook theory" mentioned in [14]. In Figure 4 the diagram shows a typical scheme where the cold and humid air from the Pacific Ocean is forced towards a mountain range (the Andes in this case, Chile area).

As in the foehn, the air cools dry-adiabatically until it reaches saturation, then the rise is wet-adiabatically until the air reaches the crest of the mountain, so clouds are formed and rain and snow precipitation occurs. At the lee of the range (Argentina area) the air descends and is heated dry-adiabatically, hence the air becomes dry and warm over the crest, or the piled-up clouds form the "zonda wall" some kilometers to the east.

Snow precipitation and "white wind" can be detected in this area. In some lower levels, zonda blows in an intermittent lapse ("pulsating zonda”) and upon reaching the plains it blows continuously (“continuous zonda”). Thermal inversion on the plains may or may not be broken depending on several variables and factors.

\subsection{A Classic Event}

In Norte [1] (chapter 3) a typical event of moderate intensity was selected. The episode occurred in San Juan 
province and in the northern area of Mendoza province and reached the capital cities of both provinces in the afternoon of August $23^{\text {rd }}$, 1983. The situation shows the most frequent conditions in the area. In San Juan Aero the temperature went up to $31^{\circ} \mathrm{C}$, the relative humidity went down to $10 \%$, the speed of the wind gusts reached a maximum of $60 \mathrm{~km} / \mathrm{h}$, and the wind lasted 10 hours. In Mendoza Aero the maximum temperature climbed to $28.3^{\circ} \mathrm{C}$, relative humidity descended to $21 \%$, and wind gusts did not surpass $50 \mathrm{~km} / \mathrm{h}$ with 4 hours of duration.

Figure 5 shows the surface synoptic situation at 12 UTC (9 local time) that is similar to other analyzed situations when the zonda appears or is about to appear in the stations of Cuyo plains. Water vapour distribution is identified in the $850 \mathrm{hPa}$ chart (Figure 6), where a closed nucleus of high humidity can be observed on the windward of the Andes, and another closed dry air nucleus is observed on the lee side.

The difference in humidity between Quintero (Chile) and Mendoza Aero is continuous in the upper layers at $700 \mathrm{hPa}$ level (not shown), and it disappears at $500 \mathrm{hPa}$ level (Figure 7). A cold front is next to the Andes associated to a migratory depression placed in front of the Chilean coast. The depression is cold and develops to the 250 hpa level (Figure 8). At $230 \mathrm{hPa}$ (not shown) a jet stream crosses the continent from Mendoza Aero to the River Plate in the east of the country with wind velocities between 90 to 110 knots.

The zonda was produced by the rise and subsequent major orographic descent of a prefrontal air mass strongly baroclinic. In the summits the wind starts like a cold cathabatic wind of the "bora" type [3]. When it warms up adiabatically in its descent, it reaches the plains with high temperatures (this is clear due to the snowstorm with a pronounced cooling and the "white wind" in the border between Chile and Argentina) (Figure 5). In this case the zonda belongs to the kind of wind regarded as genetically cold [24].

The associated synoptic situation is characterized by:

- A long wave ridge to the east of the region and a coming short wave trough.

- A moderate northern flow in central Argentina.

- A migratory depression entering the north of Patagonia with a cold front coming closer to the Andes from W-SW.

- A warm front in northern Argentina.

The NAL is clearly defined [25] and is located in its normal seasonal position. Surface atmospheric pressure is lower than the normal value of the mean field in all the Argentine territory with significant anomalies in Cuyo, Neuquen and the southwest Chilean islands.

A strong baroclinicity in the zone produces a marked vertical wind shear and strong wind transversal components to the Andes together with the proximity of the jet stream, indicating that the warm front plays an important role in the occurrence of zonda.

\subsection{FNZ Categories}

Norte [1] defined zonda wind categories based on the maximum gust registered in any event. Actually, the categories are named as FNZi (i between 1 and 4). Events are considered:

- Moderate (FNZ1) when the maximum gust is less than or equal to $35 \mathrm{kt}(18 \mathrm{~m} / \mathrm{s})$.

- Severe (FNZ2) when the maximum gust is greater than $35 \mathrm{kt}(18 \mathrm{~m} / \mathrm{s})$ and less than $50 \mathrm{k}(25 \mathrm{~m} / \mathrm{s})$.

- Very severe (FNZ3) when the maximum gust is equal to or greater than $50 \mathrm{kt}(25 \mathrm{~m} / \mathrm{s})$ and less than $65 \mathrm{~km} / \mathrm{h}$ $(33 \mathrm{~m} / \mathrm{s})$.

- Extremely severe or catastrophic (FNZ4) when the maximum gust is greater than $65 \mathrm{kt}$ (33 m/s).

\subsection{Two Examples of Non-Classic Episodes (FNZ3 and FNZ2 Events)}

Severe episodes are fortunately not frequent but can occur at any time of the year, may cause plenty of problems, and may endanger the safety of the affected people's property and lives.

A winter FNZ3 (and in some places FNZ4) episode occurring on July $11^{\text {th }}$, 2006, has been thoroughly studied by Norte et al. [2]. The following figures show some aspects of this extremely severe zonda wind phenomenon not extensively considered in this paper.

Figure 9 and Figure 10 indicate dew point temperature and atmospheric pressure evolution before, during, and after the event in Mendoza and San Juan Aero, respectively. In San Juan Aero the episode was longer, drier and warmer than in Mendoza Aero, starting before and ending later.

Figure 11 shows wind velocity and direction and Figure 12 maximum gust and its direction for San Juan 


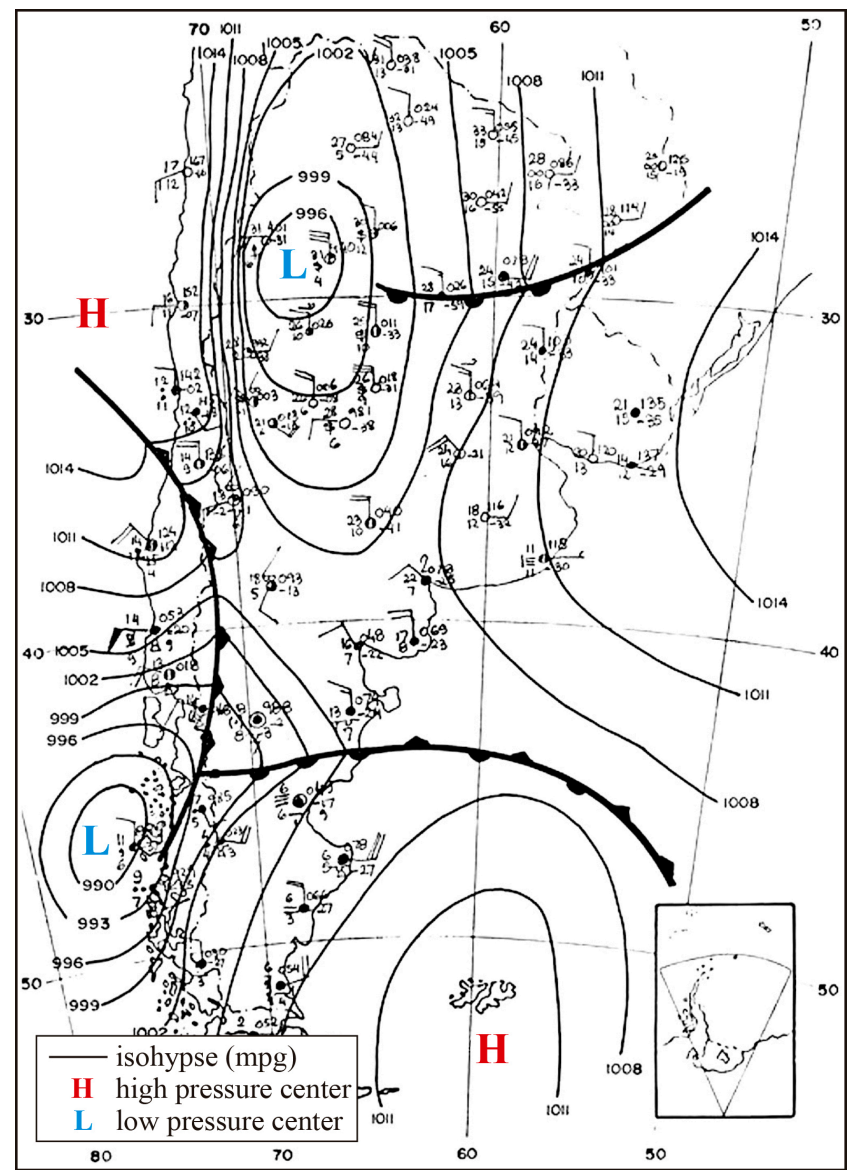

Figure 5. Surface synoptic situation at 12 UTC on August $23^{\text {rd }}, 1983$.

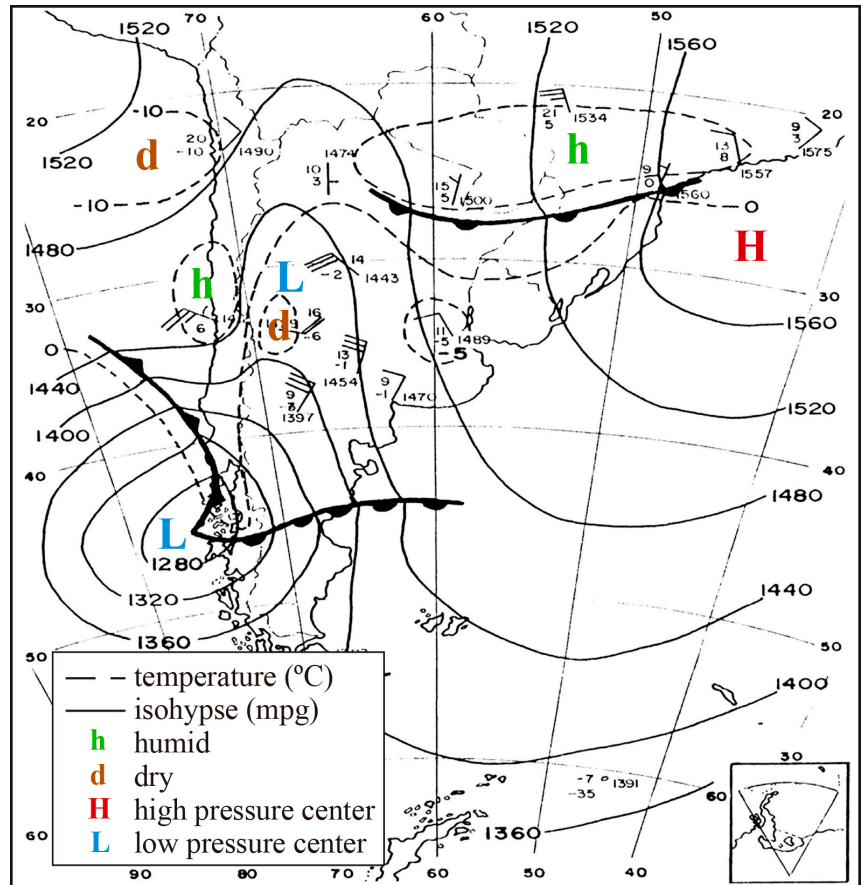

Figure 6. $850 \mathrm{hPa}$ level chart at $12 \mathrm{UTC}$ on August $23^{\text {rd }}, 1983$. 


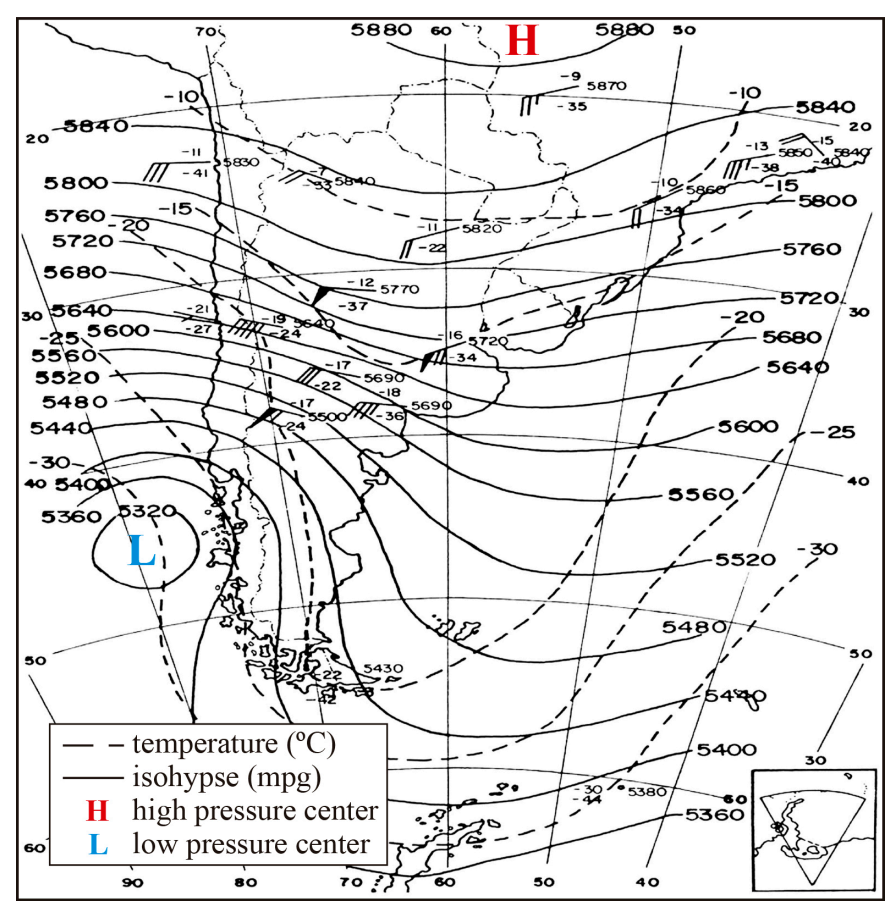

Figure $7.500 \mathrm{hPa}$ level chart at 12 UTC on August $23^{\text {rd }}, 1983$.

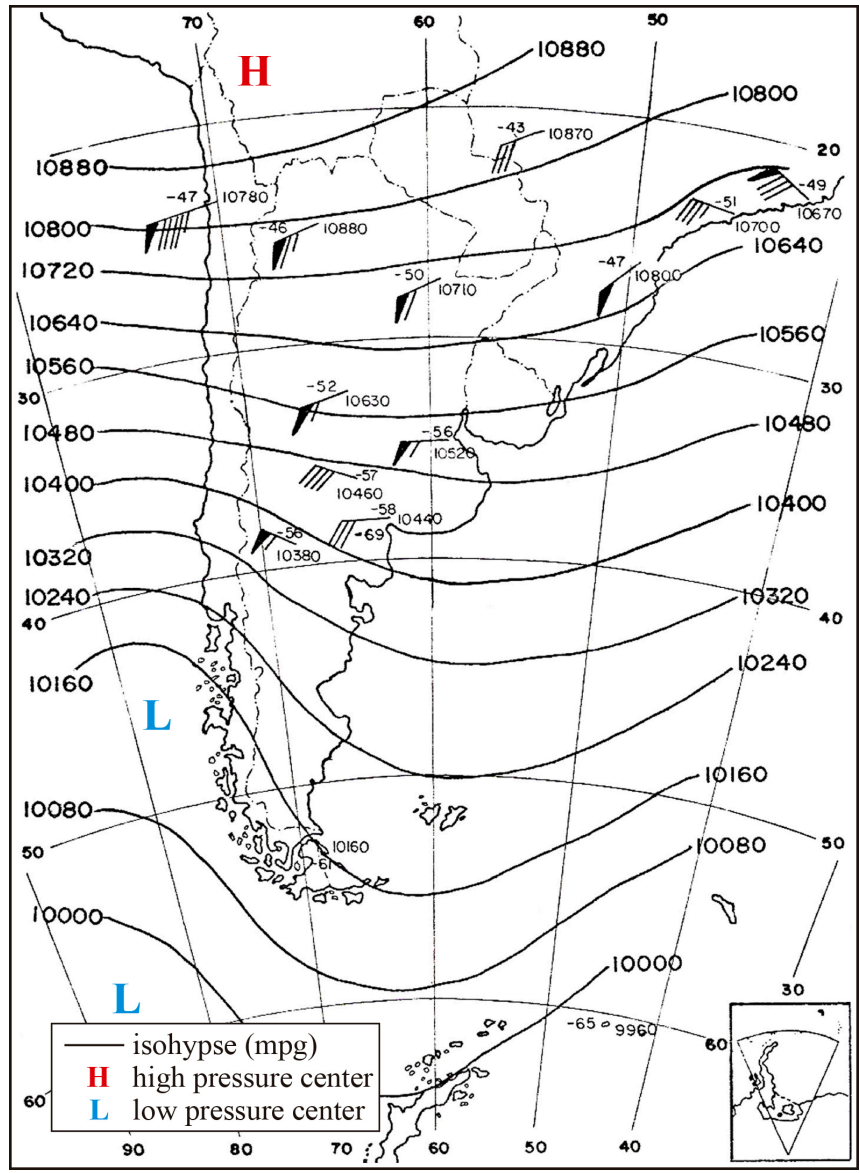

Figure 8. $200 \mathrm{hPa}$ level chart at $12 \mathrm{UTC}$ on August $23^{\text {rd }}, 1983$. 
Aero. In this station the values are also larger than in Mendoza Aero (not shown) as indicated in Norte et al. [2]. This zonda case presented heavy precipitation on the upwind side.

Figure 13 shows the evolution of the same parameters of Figure 9 and Figure 10 but for Santiago de Chile (windward of the Andes). It can be seen that cooling and saturation begin almost simultaneously with the onset of the zonda wind in Mendoza aero and extends well through the following day.

Figure 14(a) shows the marked difference in atmospheric pressure between windward and leeward in the mountain when the zonda episodes start in Mendoza and San Juan Aero. Figure 14(b) shows the behavior of the wind, displaying an increase in its speed with a constant direction in Chile before the occurrence of the zonda episode in Argentina, which confirms the process of increase prior to windward, which leads to precipitations

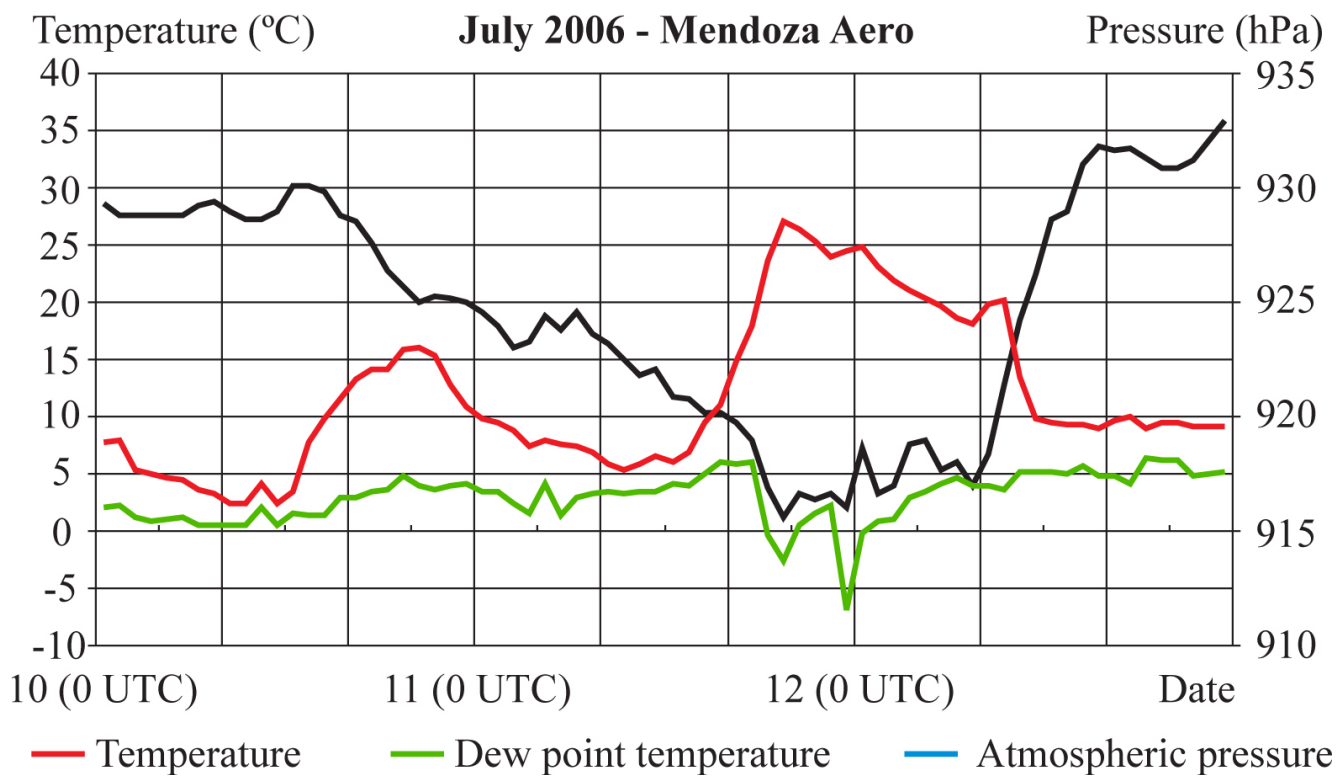

Figure 9. Atmospheric pressure, temperature and dew point evolution before, during and after zonda event of July $11^{\text {th }}$, 2006, in Mendoza Aero.

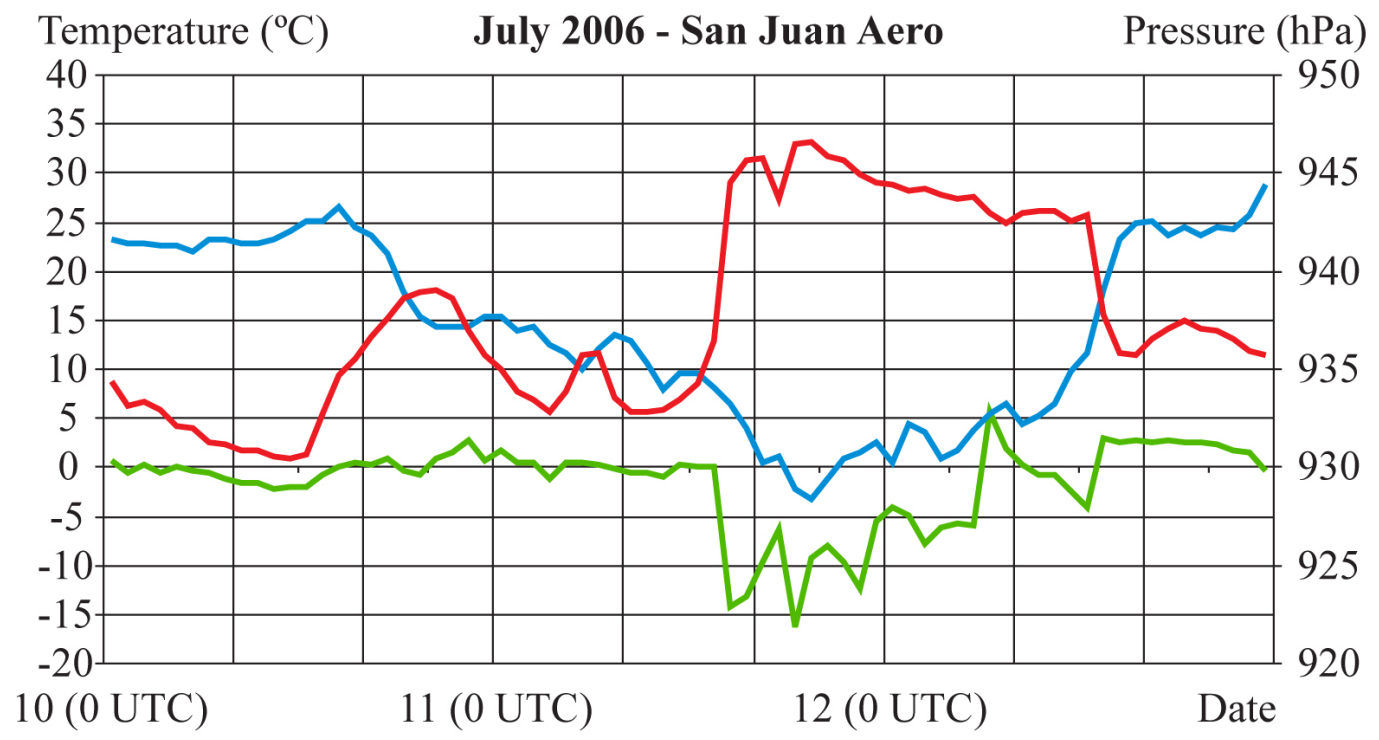

- Temperature - Dew point temperature - Atmospheric pressure

Figure 10. Atmospheric pressure, temperature and dew point evolution before, during and after zonda event of July $11^{\text {th }}$, 2006, in San Juan Aero. 


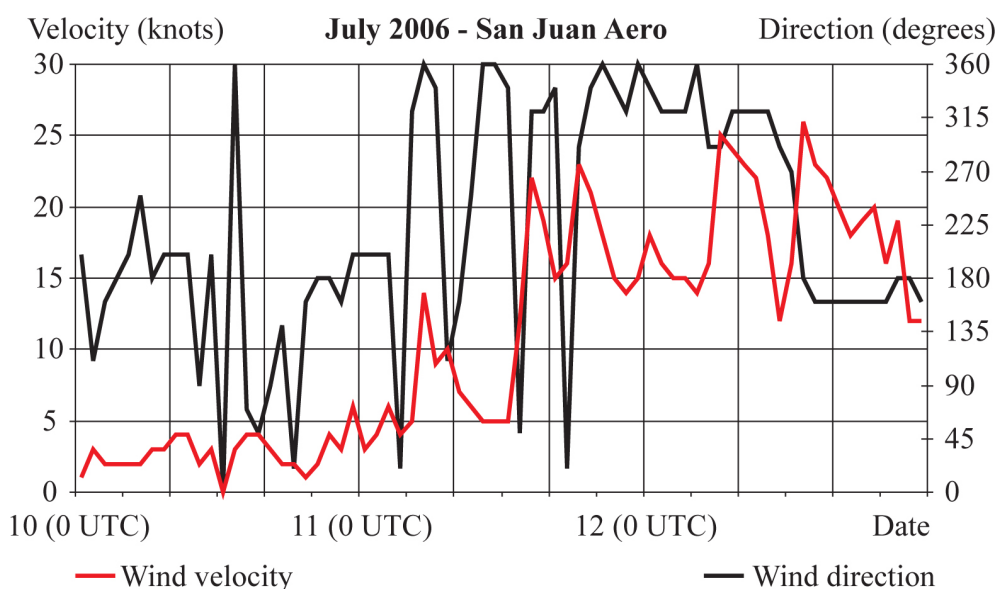

Figure 11. Evolution of wind velocity and direction before, during and after zonda event of July $11^{\text {th }}, 2006$, in San Juan Aero.

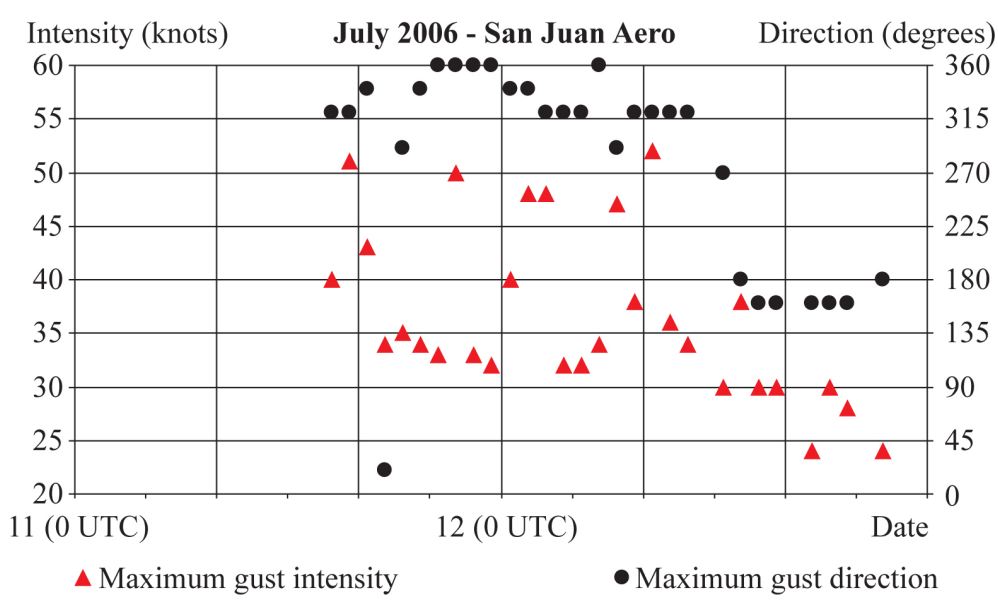

Figure 12. Maximum gust and gust direction during zonda event of July $11^{\text {th }}$, 2006, in San Juan Aero.

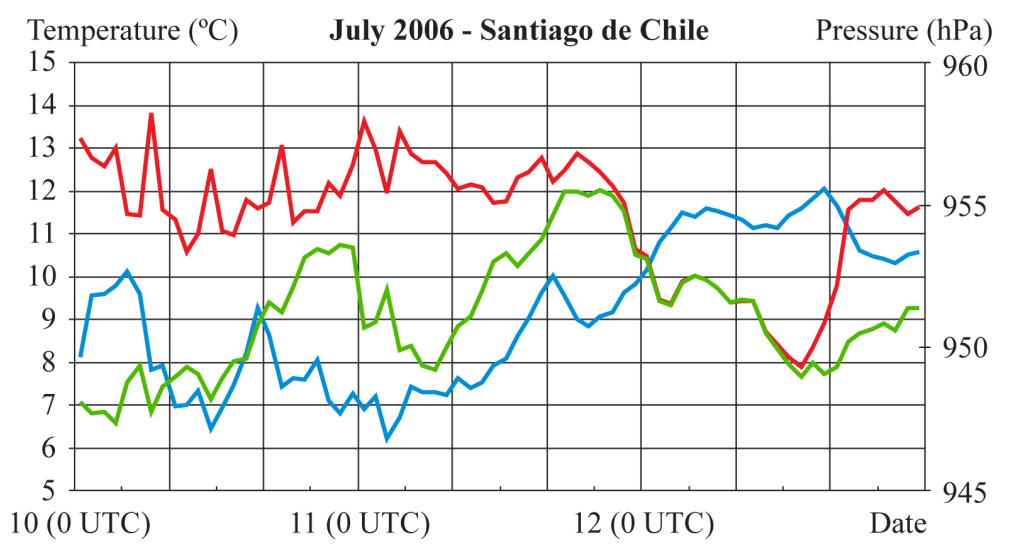

- Temperature - Dew point temperature - Atmospheric pressure

Figure 13. Atmospheric pressure, temperature and dew point evolution before, during and after leeside zonda event of July $11^{\text {th }}, 2006$, in Santiago de Chile. 


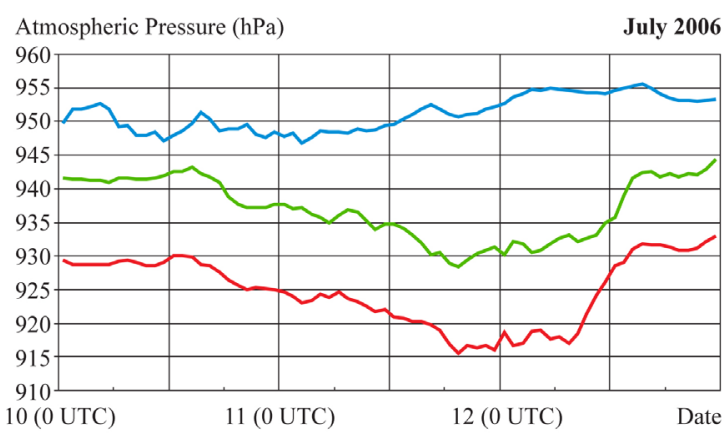

- Mendoza Aero - San Juan Aero - Santiago de Chile

(a)

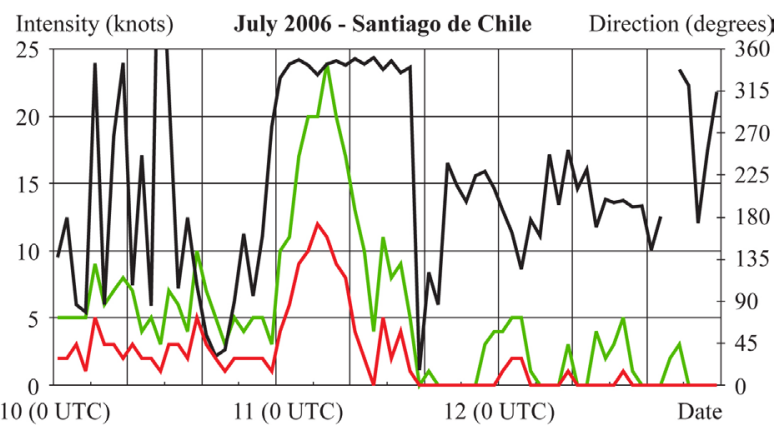

- Wind intensity - Maximum gust direction - Wind direction

(b)

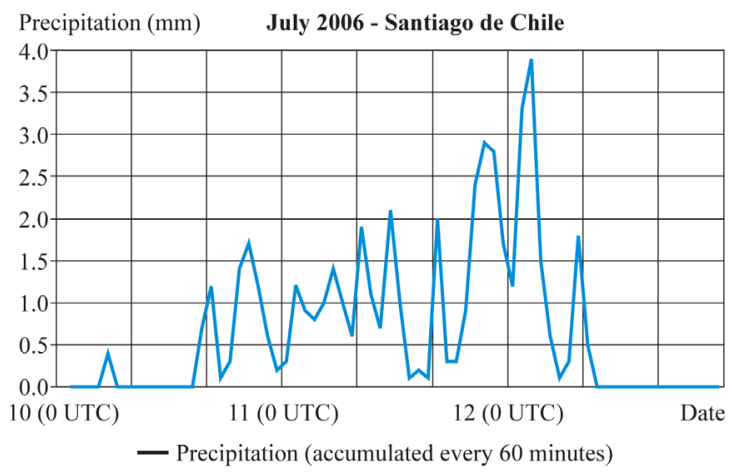

(c)

Figure 14. (a) Atmospheric pressure evolution in Santiago de Chile, Mendoza Aero and San Juan Aero; (b) Wind velocity, maximum gusts and wind direction in Santiago de Chile; (c) Accumulated precipitation in Santiago de Chile. All before, during and after zonda event of July $11^{\text {th }}, 2006$.

and the subsequent adiabatic warming at leeward. Finally, Figure 14(c) represents the accumulation of precipitation, showing that it is heavier in the apogee of the zonda, both in the Mendoza and San Juan Aero.

An uncommon summer episode that took place on Christmas Eve (December $24^{\text {th }}, 2012$ ) has also been analyzed. Figure 15 corresponds to the surface pressure analysis a few hours before the zonda wind appeared in the San Juan and Mendoza Aero. Compared to the classical situation presented in Figure 5, it can be seen that:

- The NAL is displaced to the south, to higher latitudes than its usual position, and the pressure central value is deeper than normal.

- The warm front is also located to the south, at about ten degrees of latitude.

- The migratory depression is also on the Pacific Ocean but located more to the north, about five to seven latitudinal degrees, and the associated cold front is closer to the Cuyo region.

- There are more than 25 hPa of difference between La Serena and San Juan Aero surface pressure showing a big pressure gradient.

In Figure 16, corresponding to 0 UTC on December $25^{\text {th }}$, 2012, when zonda wind is in its apogee, blowing in both cities, the NAL is deeper and the pressure difference is around $30 \mathrm{hPa}$ between the same stations. The migratory depression is over the continent and the associated cold front has crossed the Andes and is very close to Mendoza Aero.

Figures 17-19 correspond to $850 \mathrm{hPa}, 500 \mathrm{hPa}$, and $200 \mathrm{hPa}$, respectively, at the same time. A cold nucleus of $-25^{\circ} \mathrm{C}$ is centered over Chiloe Island (Chile) in $500 \mathrm{hPa}$. The cold low is centered over this place as can be seen in $200 \mathrm{hPa}$. The maximum winds of a jet stream over 140 knots are located very close to Mendoza Aero (Figure 19).

Dew point temperature and atmospheric pressure evolution before, during, and after the event in Mendoza and San Juan Aero, are shown in Figure 20(a) and Figure 20(b), respectively. Similarly to the winter event, in San Juan Aero the episode was longer, drier and warmer than in the Mendoza Aero, starting before and ending a few hours later. 


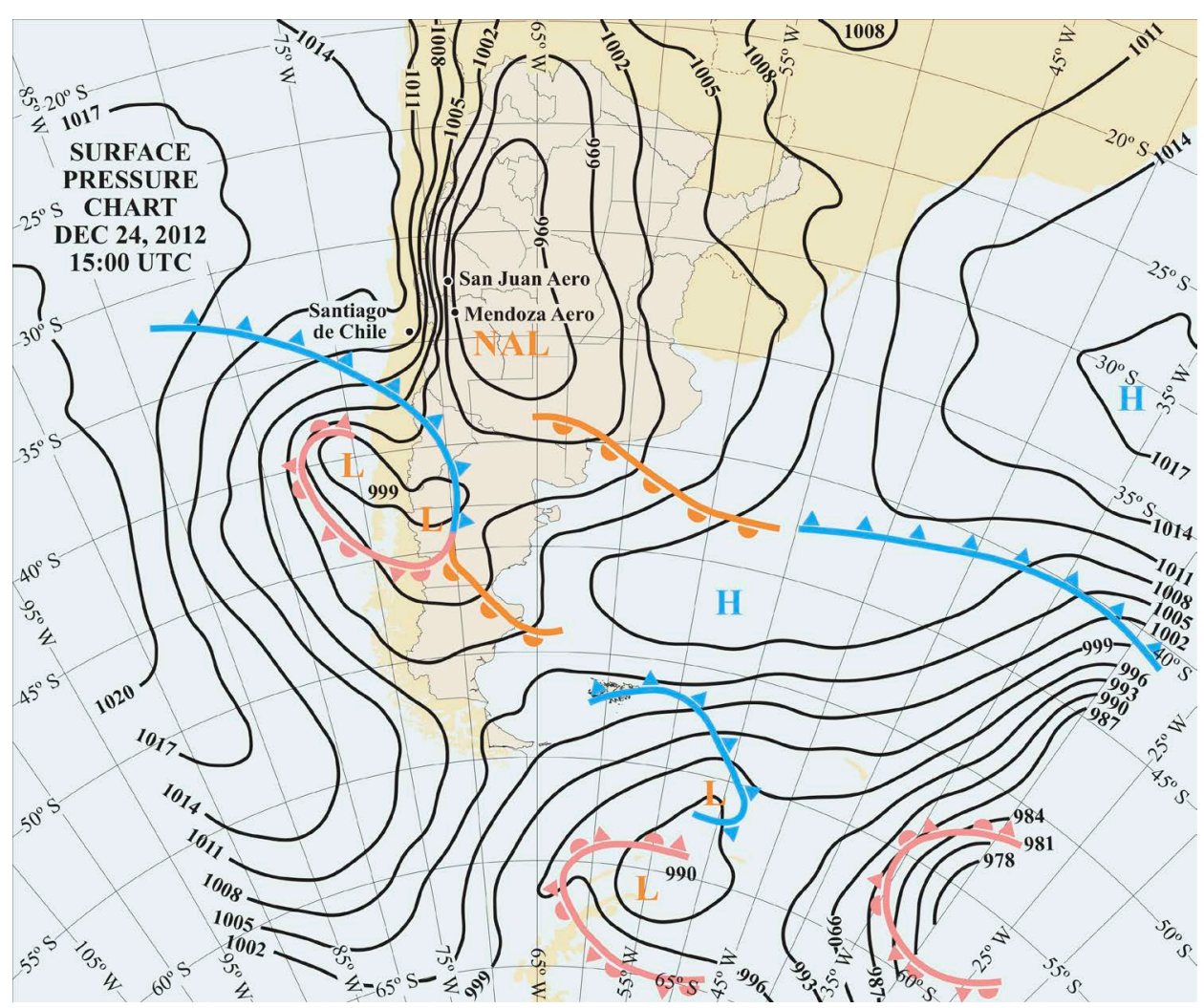

Figure 15. Surface synoptic situation at 15 UTC on December $24^{\text {th }}, 2012$.

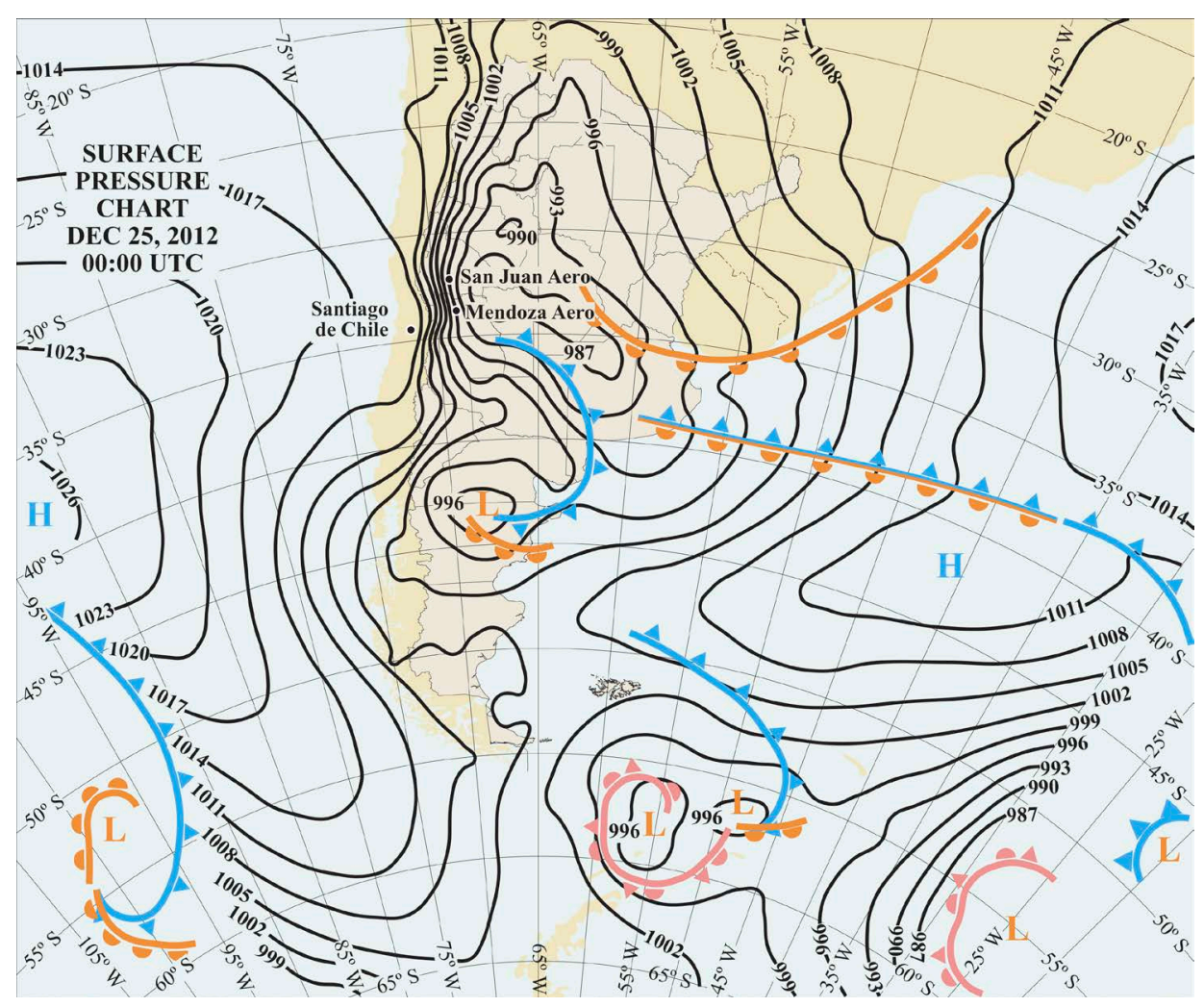

Figure 16. Surface synoptic situation at 0 UTC on December $25^{\text {th }}, 2012$. 


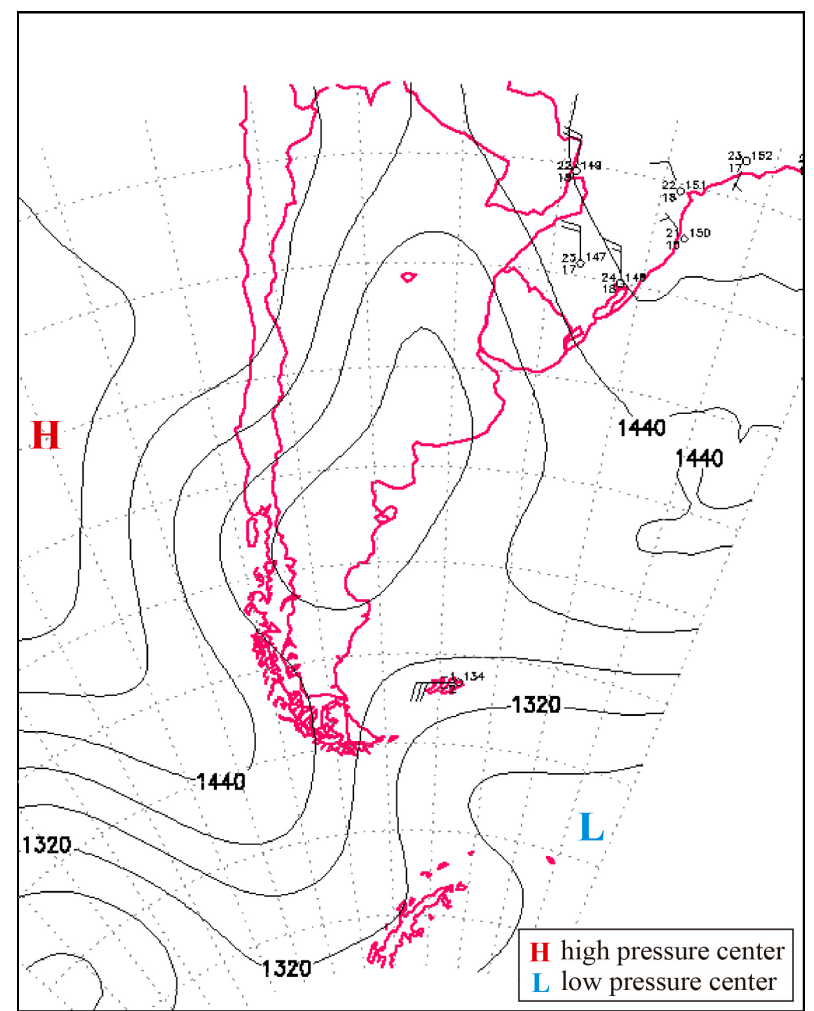

Figure 17. $850 \mathrm{hPa}$ level chart at 0 UTC on December 25 ${ }^{\text {th }}, 2012$.

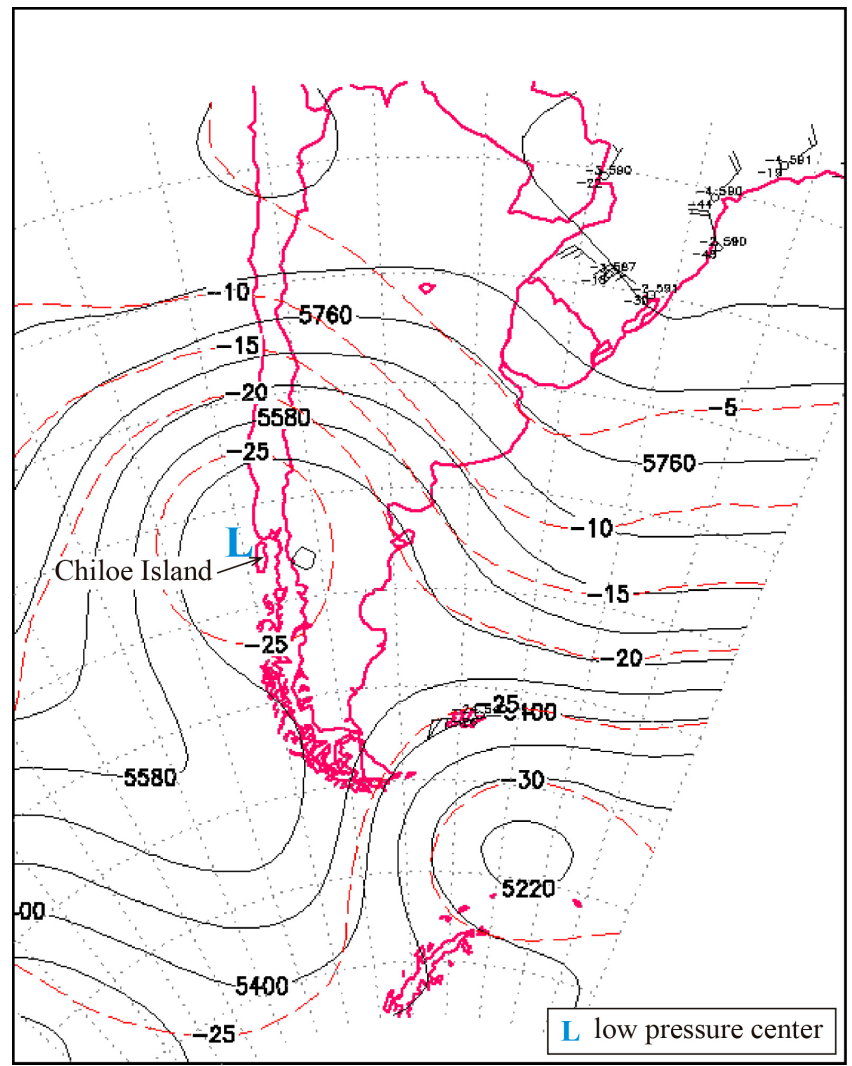

Figure 18. $500 \mathrm{hPa}$ level chart at 0 UTC on December $25^{\text {th }}, 2012$. 


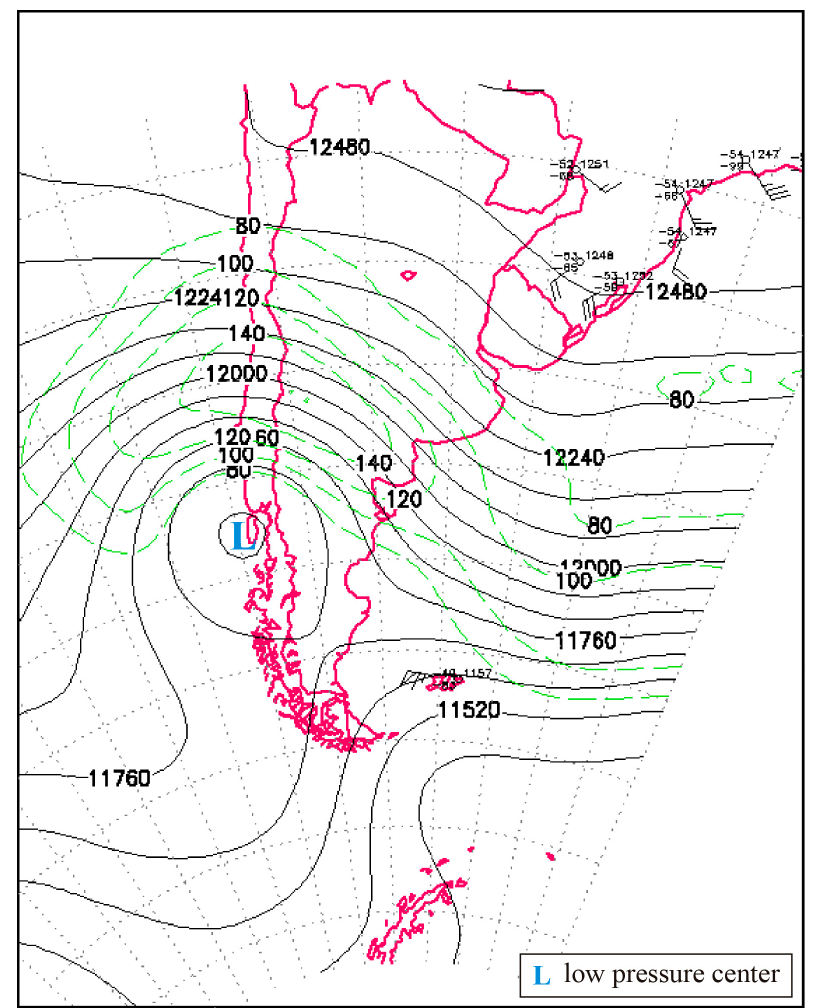

Figure 19. $200 \mathrm{hPa}$ level chart at 0 UTC on December 25 ${ }^{\text {th }}, 2012$.

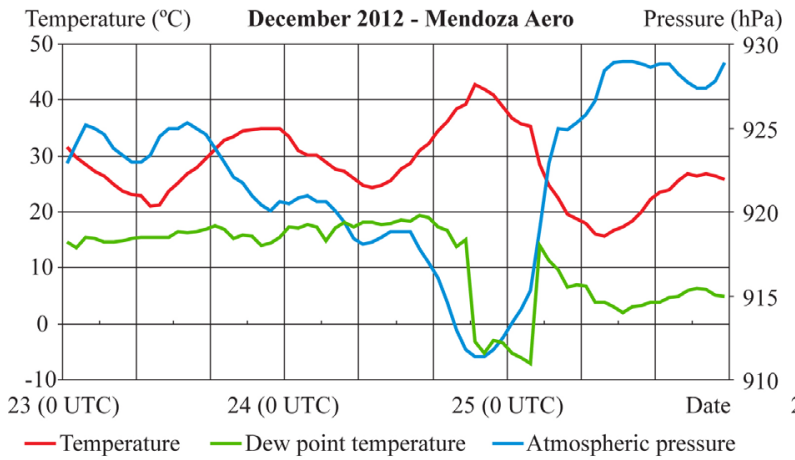

(a)

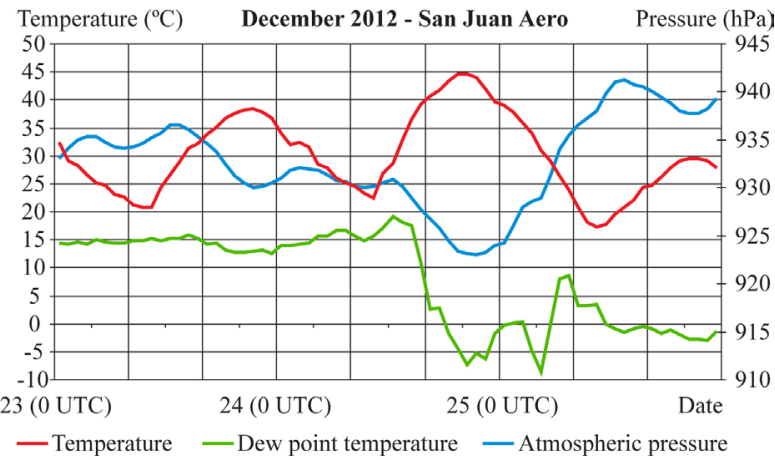

(b)

Figure 20. Atmospheric pressure, temperature and dew point evolution before, during and after leeside zonda event of December 24 $4^{\text {th }}, 2012$ : (a) in Mendoza Aero; (b) in San Juan Aero.

On this occasion the highest wind speed is recorded a short while before the end of the episode (Figure 21), and there are also significant gusts, particularly in San Juan Aero, when the cold front is coming in with southern or southeastern wind corresponding to the change of air mass (see Figure 22).

Windward to the Andes, only in Santiago de Chile a cooling of temperature is observed towards the last hours of the evening of December $24^{\text {th }}$, associated to cloudiness and to the incoming cold air, also marked by the rapid increase in atmospheric pressure in the early afternoon hours (see Figure 23 and Figure 24).

This kind of episode, of very low frequency of occurrence in the summer, does not show windward precipitations in Santiago de Chile. Leeward to the Andes it co-existed with convection processes for a few hours (with associated cloudiness of vertical development: cumulus nimbus) recorded very close to the subsidence area generated by the zonda wind. Maximum temperatures of $45.3^{\circ} \mathrm{C}$ and $43.2^{\circ} \mathrm{C}$ in San Juan and Mendoza Aero, respectively, are ranked within the highest values in existing records. 


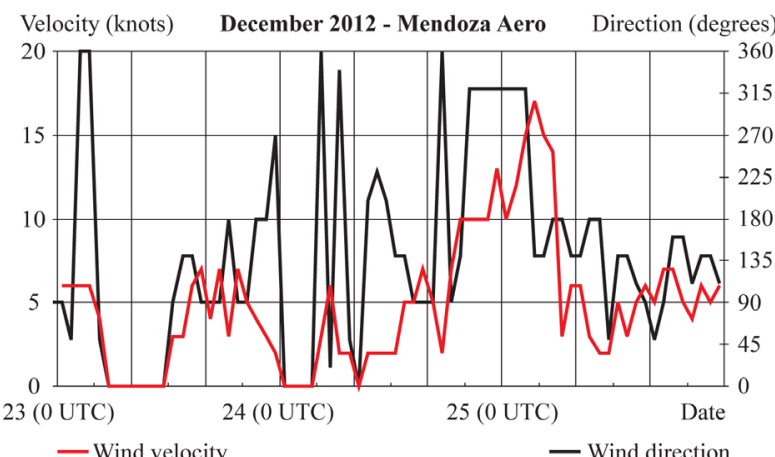

(a)

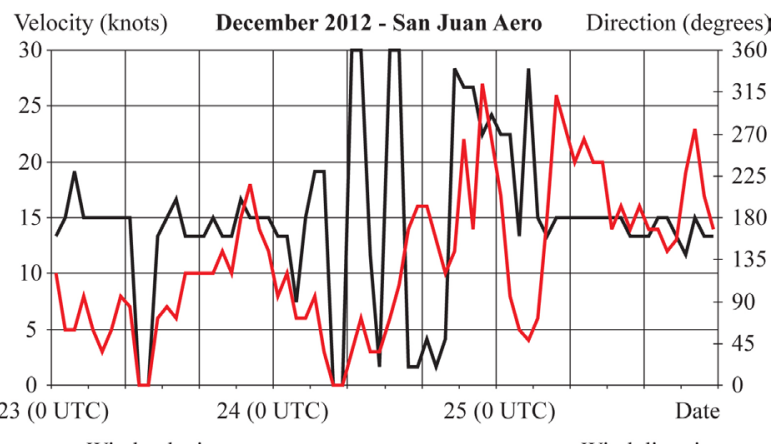

- Wind velocity

(b)

Figure 21. Velocity and wind direction evolution before, during and after zonda event of December 24 ${ }^{\text {th }}$, 2012: (a) in Mendoza Aero; (b) in San Juan Aero.

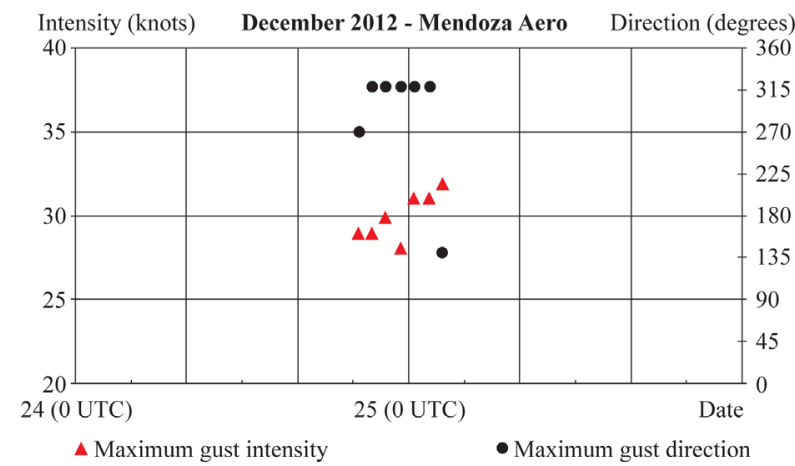

(a)

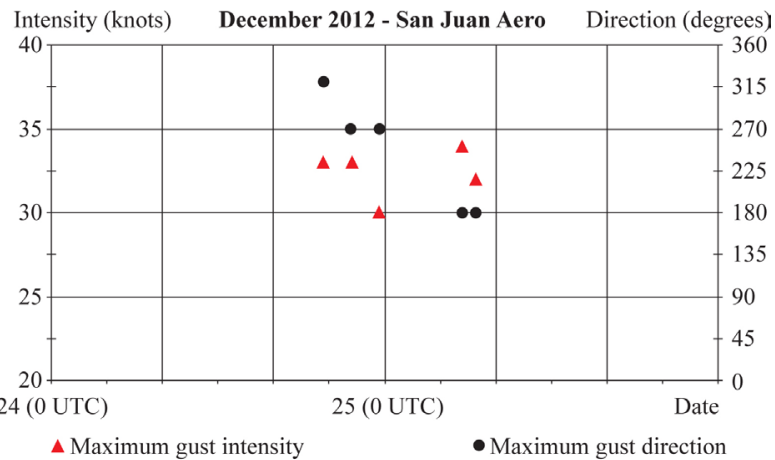

(b)

Figure 22. Maximum gust and gust direction during zonda event of December $24^{\text {th }}, 2012$ : (a) in Mendoza Aero; (b) in San Juan Aero.

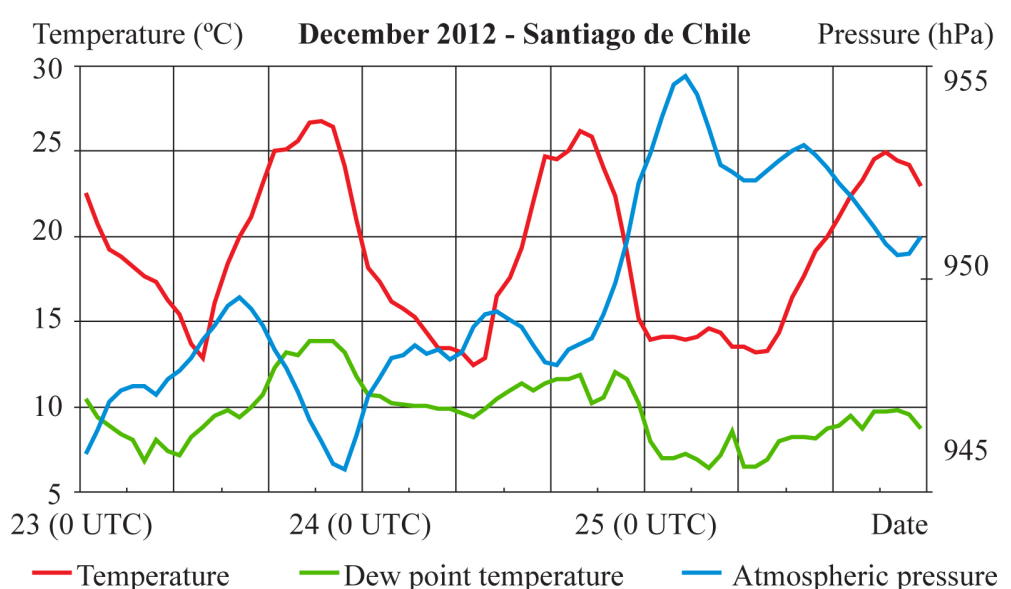

Figure 23. Atmospheric pressure, temperature and dew point evolution before, during and after leeside zonda event of December $24^{\text {th }}$, 2012, in Santiago de Chile.

\section{Zonda Dynamics}

\subsection{Lee-side Motion}

Like in the Alps, the least understood mechanism in flow dynamics is the behavior of the air masses after passing the mountain ridge in the Andes. Following Steinacker [26], who compiled six different theories about it, 


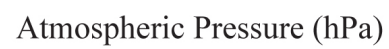

December 2012

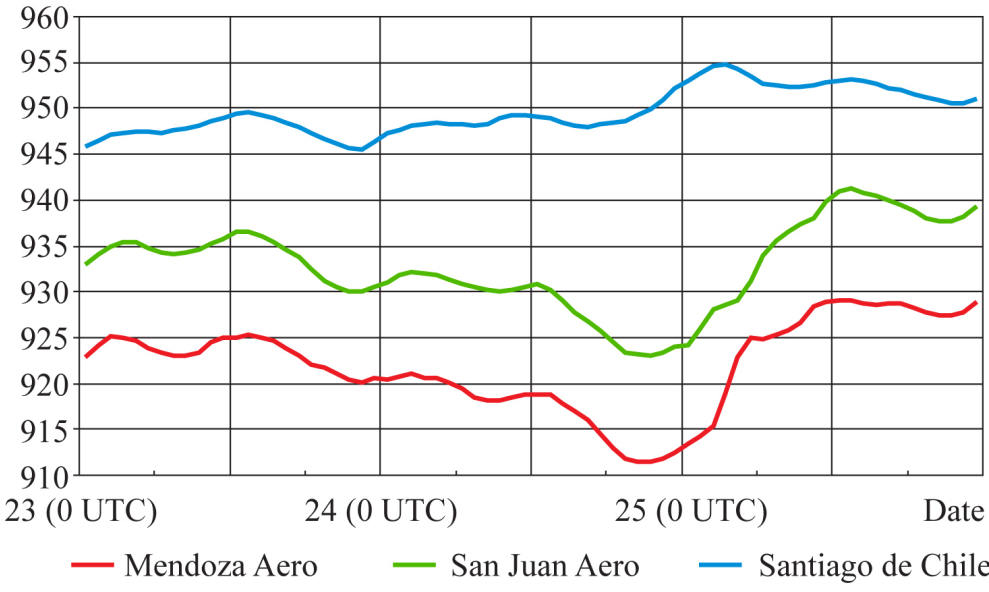

Figure 24. Atmospheric pressure evolution in Santiago de Chile, Mendoza Aero and San Juan Aero before, during and after leeside zonda event of December $24^{\text {th }}, 2012$.

two of them could be the typical schematic representation for the zonda wind in Argentina. The first one is the "waterfall" theory (see Figure 4, about the conceptual model) and the other could be the "hydraulic jump" theory.

Seluchi et al. [10] include an exhaustive analysis of the physical mechanisms which took place during three different zonda events. The vertical gradient of potential temperature, the magnitude of vertical velocities, and the analysis of the behavior of "Froude number" linked to the flow over orographic obstacles have been calculated:

$$
F r=\frac{U}{N H}
$$

where $U$ is the velocity of the wind perpendicular to the obstacle, $\mathrm{H}$ is the height of the mountain "seen” by each pressure level (distance between the level and the top terrain), and $\mathrm{N}$ is the Brunt-Vaisala frequency. The square of the Froude number is proportional to the ratio between the kinetic energy and the potential energy of the flow. A high $\mathrm{Fr}(\mathrm{Fr} \geq 1)$ implies that the flow has enough energy to traverse the mountain barrier whereas a low Fr characterizes a situation of "orographic blocking”.

At present, the Eta/PRM model is calculating this parameter operatively.

\subsection{Interaction with Cold Pool}

As in the European Alps, when zonda winds descend in the lee of the Andes ridge, they meet cooler and stagnant air. The metropolitan area of Mendoza city is in a relative orographic depression, and oftentimes zonda cannot arrive at the surface. It stands around 500 or 1000 meters over the city surface. On these occasions people say “está zondeando" (“it’s zonding”).

In Norte [1] (chapter 2), a "high zonda day" (HZD) for Mendoza city is defined as the phenomenon which happens in mountain localities and does not go down to the plains. High zonda is more frequent during the winter months. On the other hand, if zonda is blowing in the city, it is supposed to be blowing in the mountains, too. Only 5.7\% of the HZD events reach down Mendoza Aero station. For this reason visibility is reduced during HZD, and smog and haze are frequent because the thermal inversion cannot be broken. If zonda flow increases, or if there is heating by convection (especially in spring), the cool or cold pool disappears.

\subsection{Dimmerfoehn}

These kinds of conditions are not found in Argentina. There are no zonda events in Mendoza or San Juan cities if it is raining or snowing. A similar situation to "dimmerfoehn” can only be found in mountain areas where "pulsating zonda” is blowing and some gusts are interspersed with snow showers. In few events (rare occasions) 
of FNZ2 or FNZ3 category, especially in wintertime and immediately after zonda wind was over, precipitation began in Mendoza Aero.

\subsection{Waves}

There are few studies about orographic waves over the Andes related to the zonda wind. Silva [27] in her MSc dissertation analyzed zonda cases and the lee waves using the Eta/CPTEC model and evaluating some parameters like the Froude number and Scorer parameter $(l)$.

$$
l^{2}=\frac{1}{u^{2}} \cdot \frac{g}{\theta} \cdot \frac{\mathrm{d} \theta}{\mathrm{d} z}
$$

For zonda wind to occur, certain atmospheric conditions are necessary, such as atmospheric stratification and that the square of the Scorer parameter be higher than the mountain wave number $(k)$.

$$
k=\frac{\pi^{2}}{4 H^{2}}
$$

Silva analyzed the zonda event occurred over Mendoza city on August $9^{\text {th }}$, 1999, and observed that during zonda wind occurrence, $l^{2}$ had positive values between $600 \mathrm{hPa}$ and $400 \mathrm{hPa}$ levels.

Recently, Norte et al. [28] chose four representative cases (including those mentioned in 4.4) trying to show the main differences (if any) between summer and winter zonda events, and between severe and moderate cases for each season.

This exploratory analysis intends to identify the forcing mechanisms that produce waves over the Andes ranging from weak to intense gravity and leading to a strong descending flow over Mendoza city. The 4-km resolution WRF model is used. For the winter season episodes, the vertical cross-section simulation corresponding to the strong case (Figure 25(a)) shows an intense gravity wave activity with a hydraulic jump structure shown by the potential temperature field. For the weak winter case (Figure 25(b)) the gravity wave activity is also

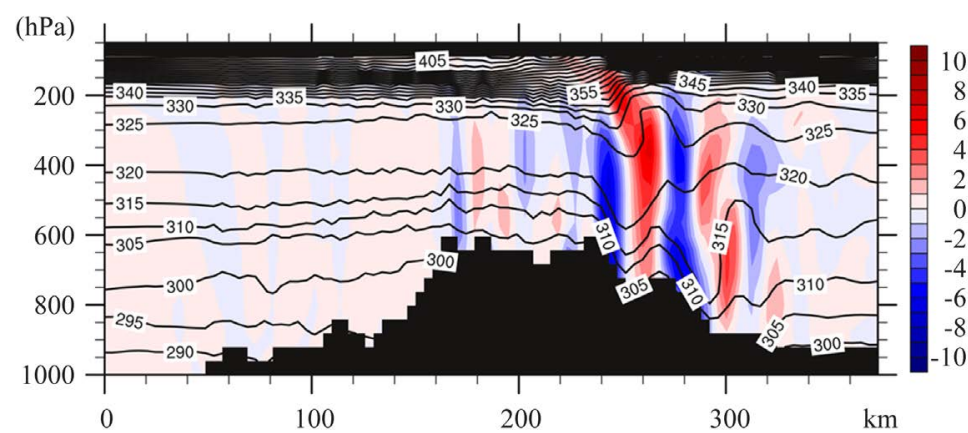

(a)

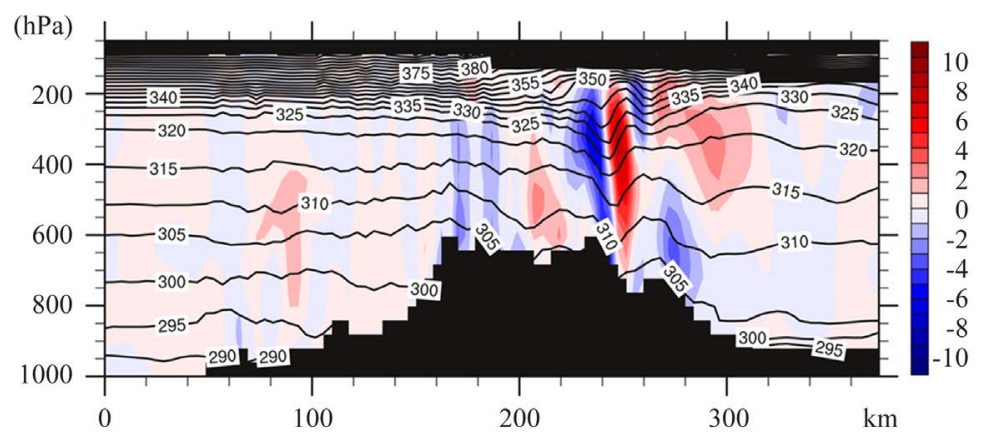

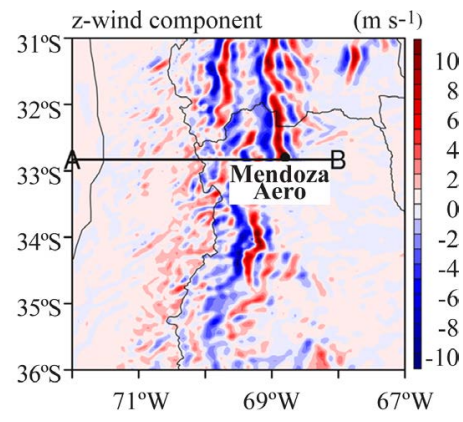

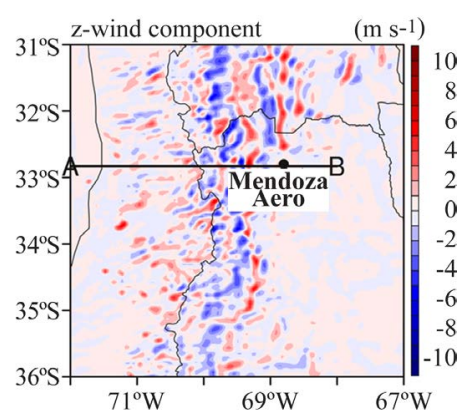

(b)

Figure 25. Horizontal and vertical analysis of gravity waves and potential temperature at Mendoza Aero latitude: (a) on July $11^{\text {th }}, 2006$; (b) on June $12^{\text {th }}, 2012$. 
weak. For the summer events, a similar situation can be seen with intense (weak) wave activity for the strong (weak) episode (Figure 26(a) and Figure 26(b), respectively). It seems that waves are more active in July than in December comparing both weak and strong events.

\section{Zonda Climatology}

In Argentina there are no maps showing zonda regions in contrast to what is shown by Richner \& Hechler [14] (in that paper, see Figure 4.21 of Austria and Southern Germany, or Figures 4.22 and 4.23 of Switzerland). This is not possible because of the low density of the meteorological network.

However, there is a climatology of zonda wind from Mendoza Aero and San Juan Aero.

The record used was 1983-2012 for Mendoza Aero and 1950-2014 for San Juan Aero.

Zonda is more frequent between May and November and there is a maximum of occurrence in spring (October for Mendoza Aero and September for San Juan Aero) (Figure 27 and Figure 31, respectively). The onset of zonda events is shown in Figure 28 and Figure 32 for these cities. The wind usually arrives at the surface after the local midday (around 17 or 18 UTC in Mendoza Aero) and two or three hours before in San Juan Aero, especially in wintertime when thermal inversion is already broken.

If zonda starts early in a winter morning, it has a longer duration and can be of high intensity category (FNZ2 or FNZ3). In Mendoza Aero duration of events is short (see the principal maximum in one hour and a secondary maximum in five hours in Figure 29). In San Juan Aero the events have a longer duration (a principal maximum of eight hours and a secondary maximum of twelve hours, Figure 33). Zonda preferably blows from the west or northwest direction (Figures 30 and Figure 34). This is quite different from the European Alps. A complete climatology of San Juan Aero can be seen in Otero \& Norte [21].

\section{Forecasting Problems}

In a rather similar manner as in the European Alps, zonda forecasting rests on the following pillars:

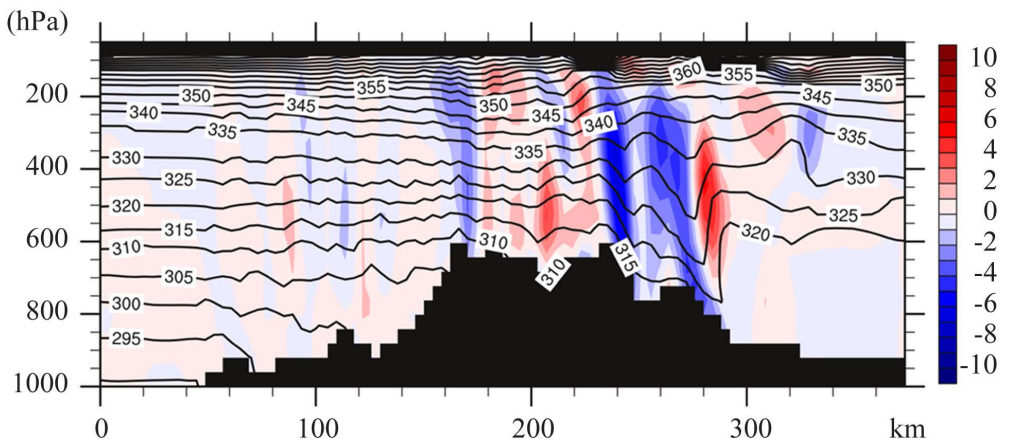

(a)

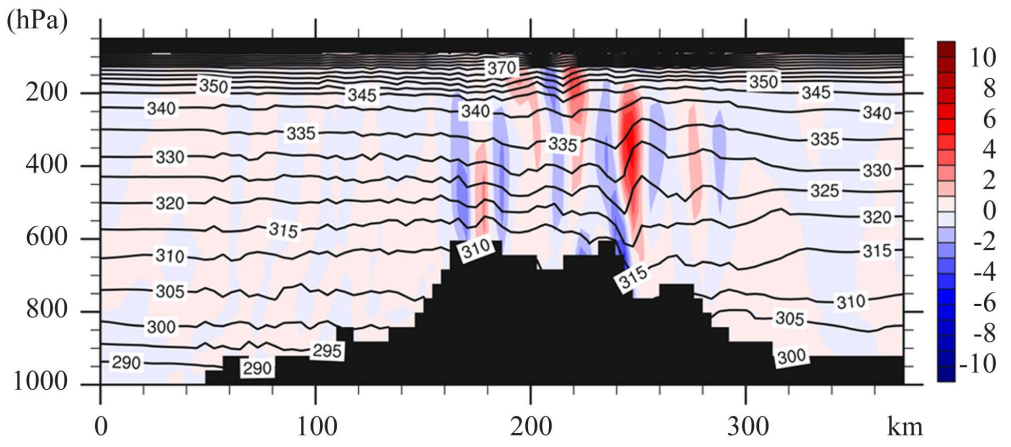

(b)
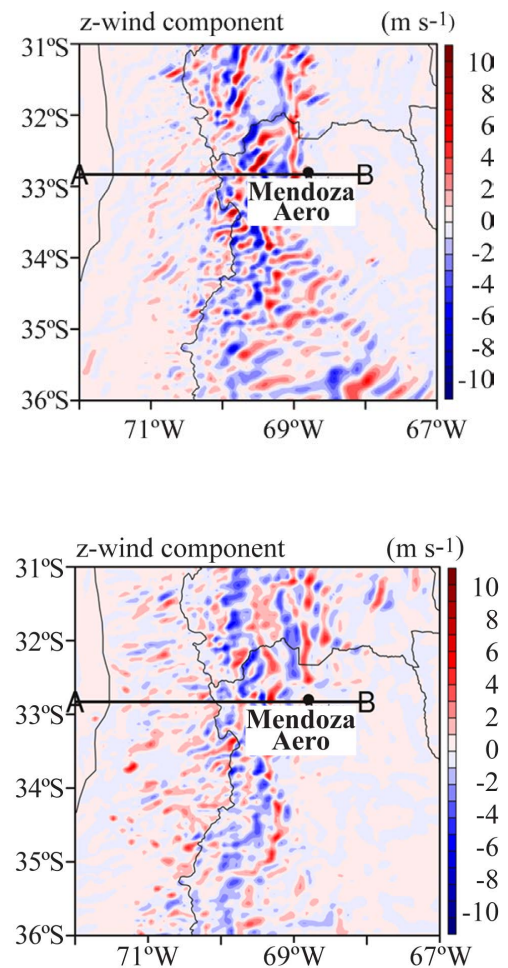

Figure 26. Horizontal and vertical analysis of gravity waves and potential temperature at Mendoza Aero latitude: (a) on December $24^{\text {th }}, 2012$; (b) on December $17^{\text {th }}, 2012$. 
Monthly Frequency and Intensity

Mendoza Aero

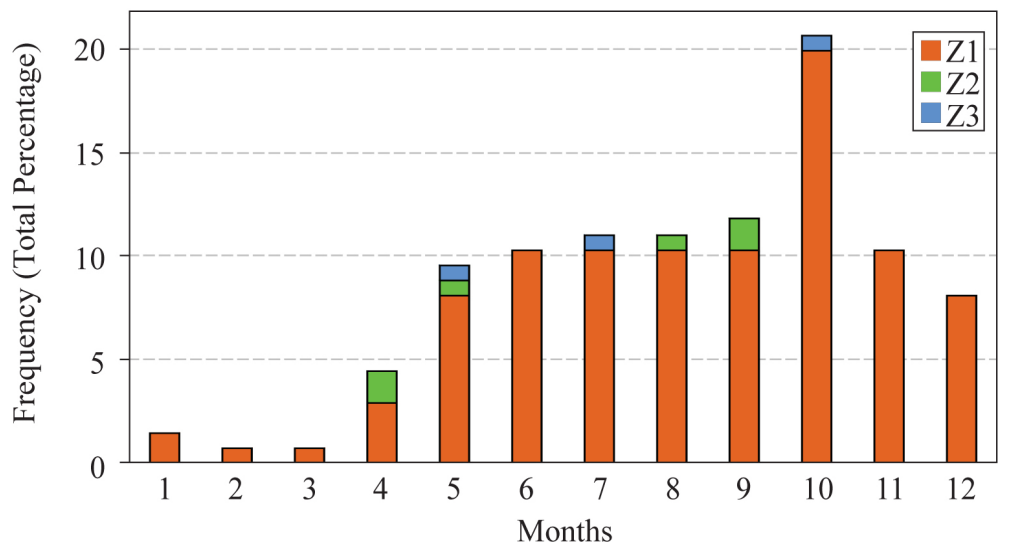

Figure 27. Monthly frequency (by intensity) of zonda in Mendoza Aero.

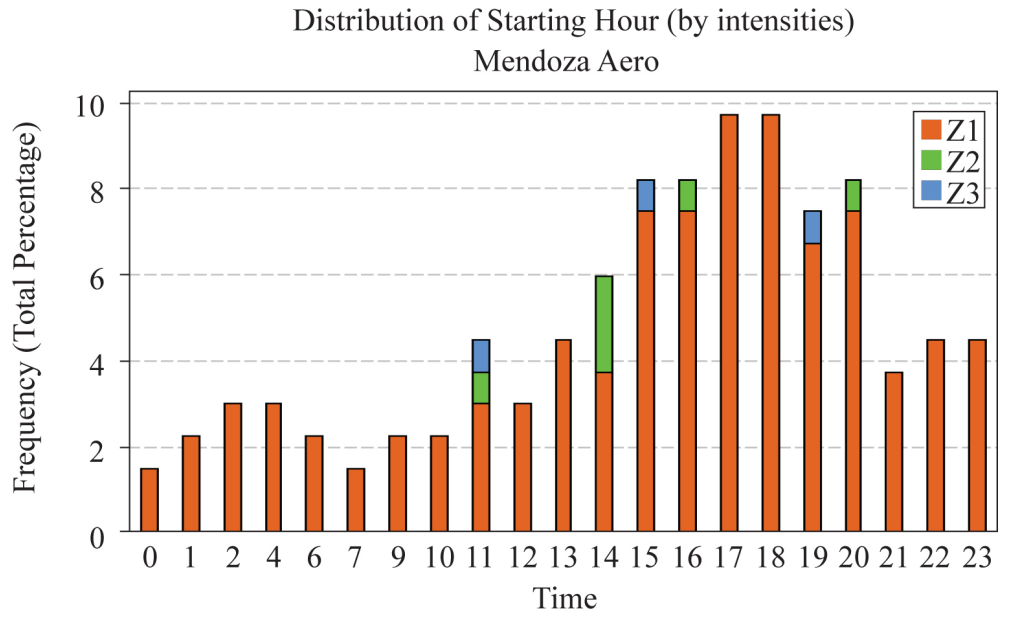

Figure 28. Time of onset of zonda events (by intensities) in Mendoza Aero.

Distribution of Duration (by intensities)

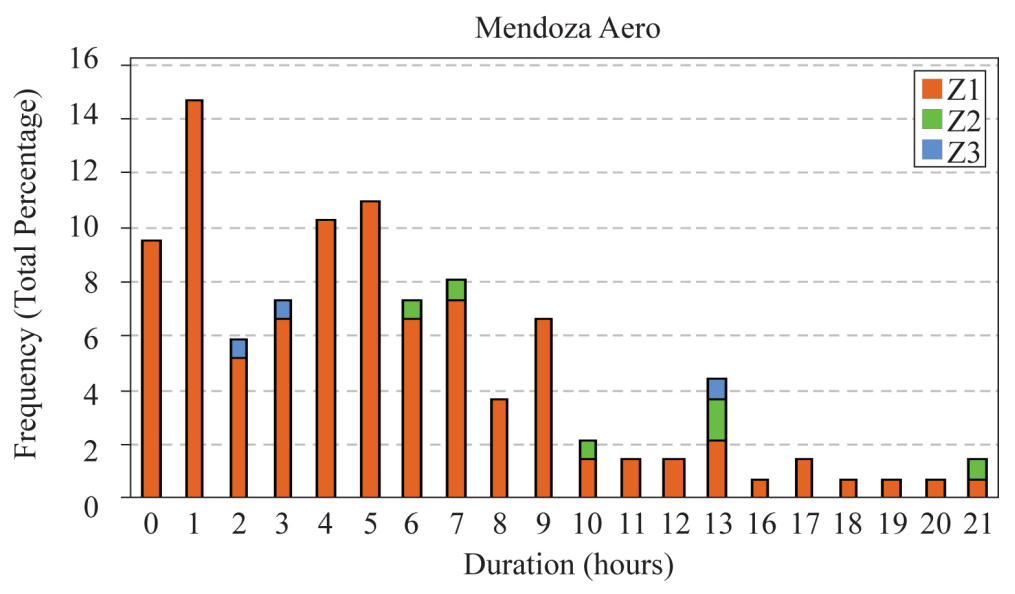

Figure 29. Frequency of duration (in hours) of zonda events in Mendoza Aero. 
Direction and Intensities Frequency

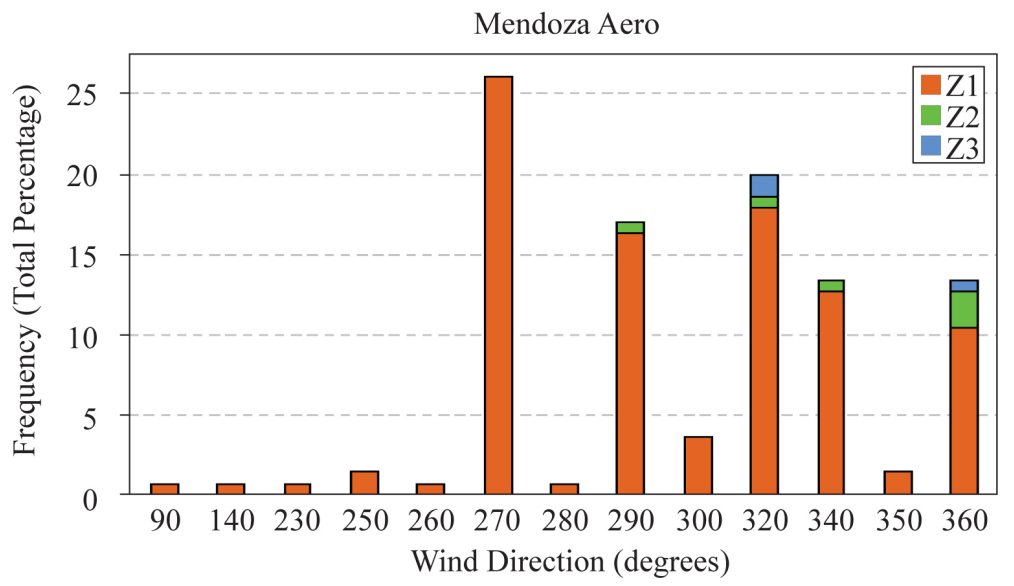

Figure 30. Frequency of direction of zonda events in Mendoza Aero.

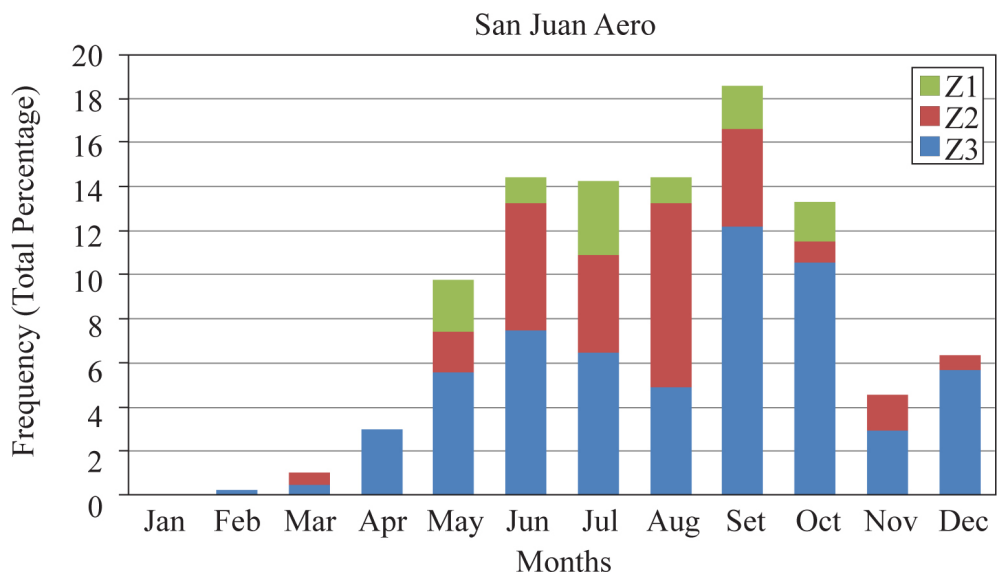

Figure 31. Monthly frequency (by intensity) of zonda in San Juan Aero.

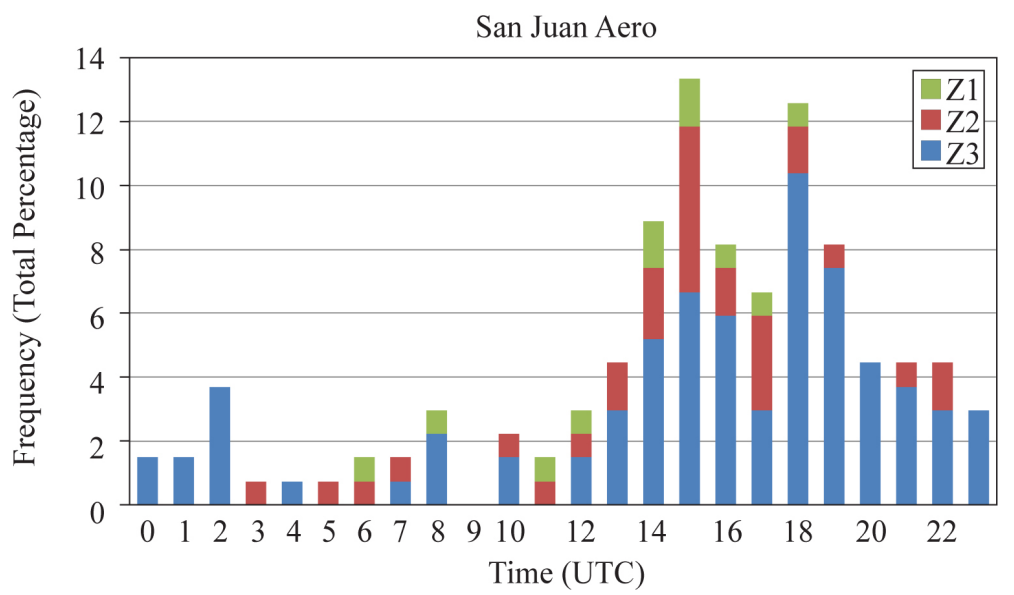

Figure 32. Time of onset of zonda events (by intensities) in San Juan Aero.

\subsection{Empirical Observational Methods}

The different evolution stages of the zonda situations can be visually identified through the form, density and 


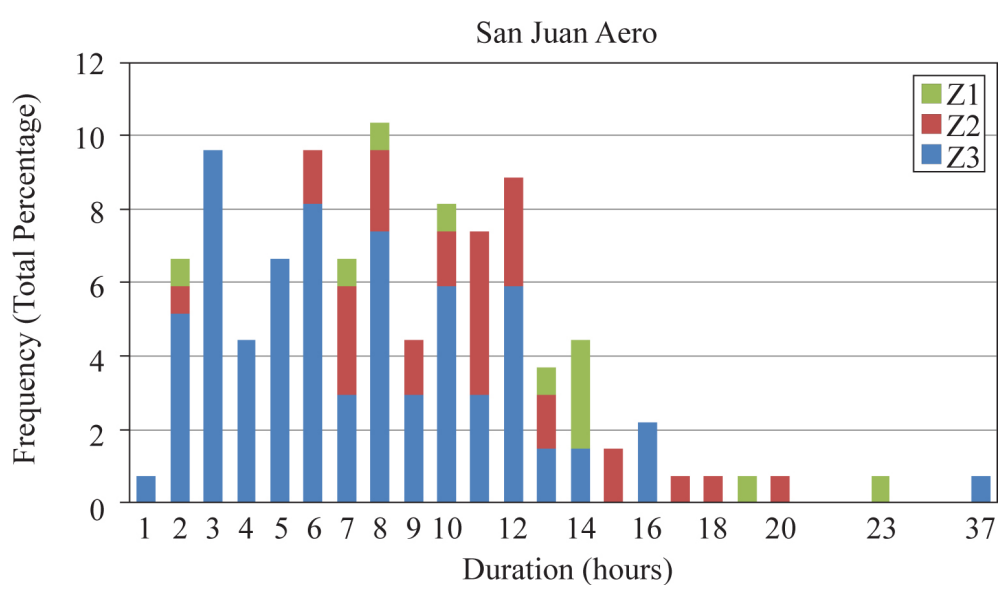

Figure 33. Frequency of duration (in hours) of zonda events in San Juan Aero.

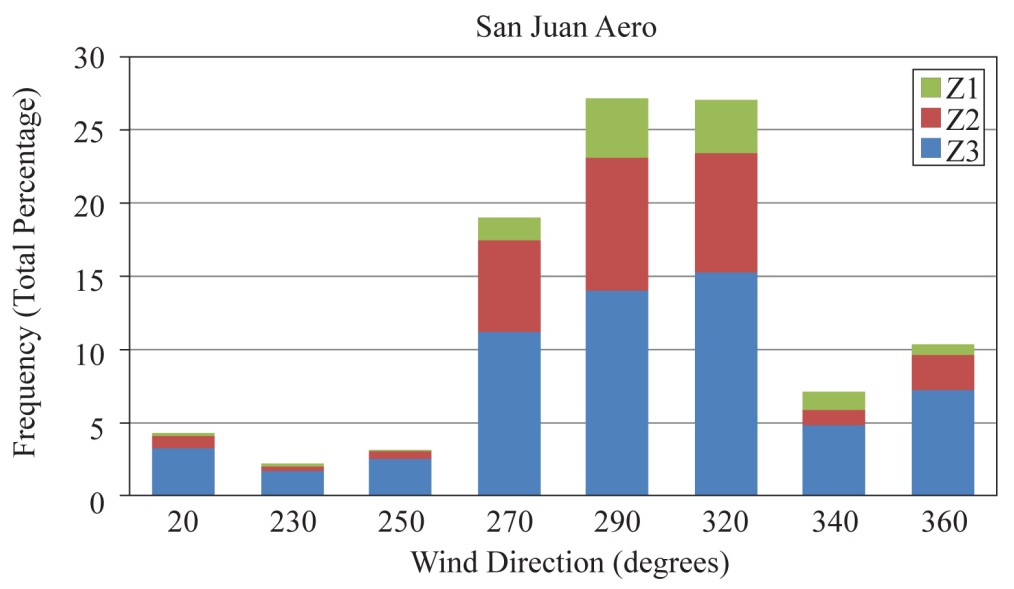

Figure 34. Frequency of direction of zonda events in Mendoza Aero.

location of certain types of clouds. The possible future developments of the phenomenon can also be inferred. The cloudiness that acquires a lenticular shape suggests "high zonda", but it is not always an observational predictor of zonda appearance in the plains. This usually occurs in the initial zonda stages (scarce altocumulus and cirrocumulus in completely clear skies).

When the lenticular cloudiness covers a greater proportion of the sky, it is more likely that the wind will descend to Mendoza or San Juan Aero. The "rotor cloud" (see conceptual model, Figure 4) indicates a well-defined and well-developed zonda and a high chance of zonda occurring in the plains. There is a certain kind of lenticular altocumulus, of noticeable thickness and well-defined borders associated to the possibility of a severe zonda category (Figure 35).

If all the zonda cloudy elements are observed from the cities (i.e., if elements such as "zonda wall", "rotor" cloud, and lenticular clouds in a diaphanous sky allow clearly visualizing the orographic features of the mountains), the probability of zonda is high. The presence of dust clouds and the advance of the zonda wall towards the zenith act as short term observational predictors.

\subsection{Synoptic Elements for Forecasting}

Some of the results obtained after thoroughly analyzing the typical or classical zonda event (chapter 3 of $\mathrm{PhD}$ dissertation [1]) of August 23 $3^{\text {rd }}$, 1983 (Figure 5) were taken into account as forecasting elements of the phenomenon in the plains. The following results should be highlighted:

- The shifting of a migratory anticyclone from the Patagonia to the northeast of Argentina.

- A trough coming from the Pacific Ocean. 


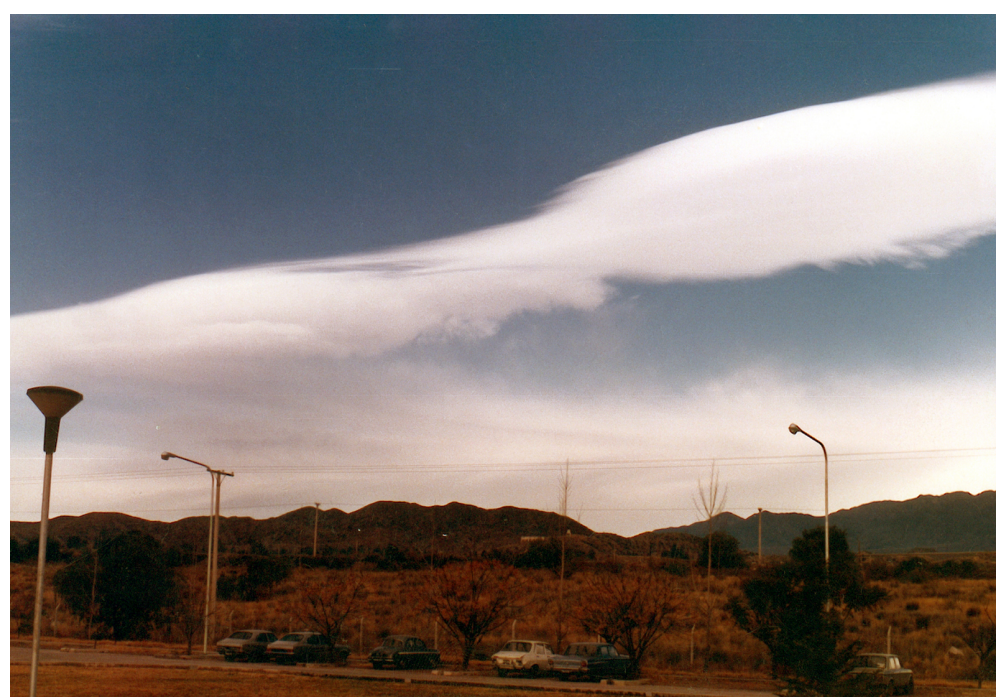

Figure 35. Typical lenticular altocumulus clouds before a severe episode in Mendoza city.

- The NAL shifts from its usual position to the south.

- A warm front in the north or northeast of the country.

- The strong baroclinicity in the Cuyo zone.

- The presence of zonda wind in high levels and in mountain areas.

- The proximity of a low pressure center coming in from the northern Patagonia with a cold front approaching the Cuyo Andes from the southwest.

\subsection{Probabilistic Method}

In Norte [1] a probabilistic method was developed. Predictors were obtained using the Stepwise Discriminant Analysis (SDA). In order to forecast zonda wind with computational methods, four groups were defined:

- Zonda group: including the days with zonda on the plains (Mendoza and/or San Juan).

- Previous 24-hour group: the day preceding a zonda day.

- Previous 48-hour group: corresponding to the day preceding that defined as the "previous 24 hours".

- The group "Others" corresponds to the rest of the series, days that do not belong to any of the groups mentioned before.

Once the groups were selected, it was necessary to know if there existed variables that would indicate unequivocally if a certain day belonged to one of the defined groups. If this classification was achieved, starting from those variables assumed as predictors, there would exist conditions to forecast the event 48 hours in advance.

A first set of predictor variables was obtained analyzing the 12 UTC pressure spatial gradients (Probabilistic Predictors PP1). Some zonal and meridional pressure differences were arbitrarily defined. These pressure differences should supposedly have an influence over the discrimination of those four groups. But only two of them were selected by the SDA: one in the meridional gradient (Chañaral minus Puerto Montt) (Figure 36) and the other almost zonal (San Juan minus La Serena). The first one gives an idea of the importance of the zonal circulation index for the classification, and especially, the depression that approaches the Chilean coast by the latitude of Chiloe Island.

The second pressure gradient in a northwest-southeast trend indicates the influence exercised over the classification group by the NAL oscillation and the shift to the south or to the north of the Pacific Ocean subtropical anticyclone with respect to their usual positions.

Another analysis was conducted taking the 12 UTC pressure values (reduced to the sea level) of the 81 stations shown in Figure 36 in order to obtain the stations that would best discriminate among groups (Probabilistic Predictors PP2). SDA rescued only five stations from the total set (Puerto Montt, Santa Rosa, Treinta y Tres Orientales, South Orkney Islands and Cabo Raper). 


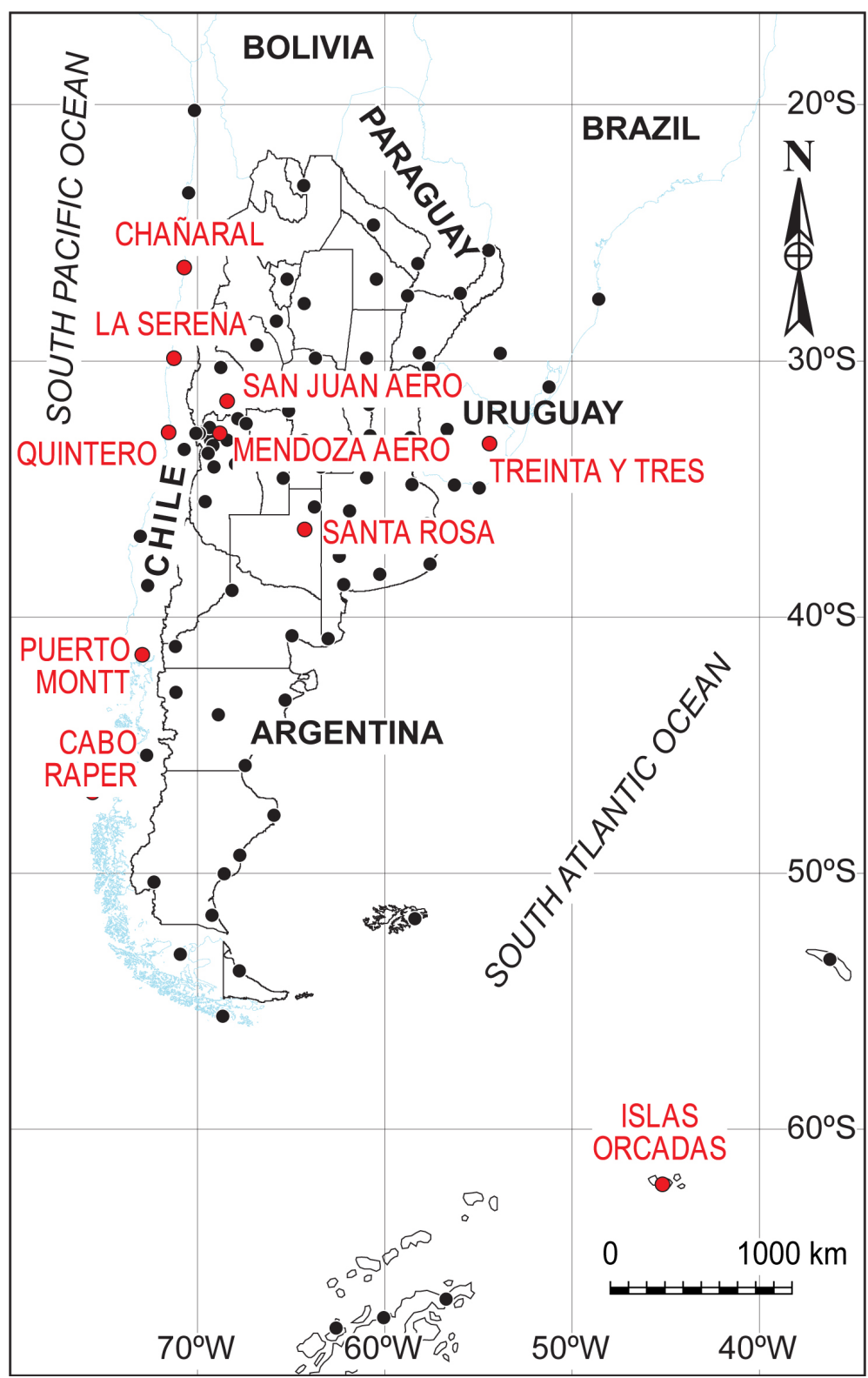

Figure 36. South America map showing the 81 meteorological stations used for the probabilistic prediction and those selected by SDA.

Puerto Montt was selected in the first place. This selection would be related to the low centers that approach the continent from these latitudes associated with cold fronts, which form one of the main synoptic elements associated to zonda days. Santa Rosa pressure station was the second, and it would be linked to the presence or not of a surface trough that identifies the zonda days from the other groups. The pressure of the Uruguayan station named Treinta y Tres Orientales would be linked to the presence or absence of the migratory anticyclone. The pressure of South Orkney Islands informs about the position of the circumpolar depressions that are then placed more to the north during zonda days.

A third set of prediction variables is obtained from the radiosonde data of Mendoza Aero station (Probabilistic Predictors PP3). The input data corresponded to the surface pressure values, plus temperature and dew point values, and the zonal and meridional components of wind on surface, and the fixed levels including $200 \mathrm{hPa}$. From the 53 variables considered, SDA only rescues four as relevant to discriminate and to act as predictors: surface pressure, dew point depression at $850 \mathrm{hPa}$ level wind, meridional component at the same level, and zonal 
wind component at $400 \mathrm{hPa}$ level.

The method has selected surface pressure as a significant variable. This would be linked to the fact that the decrease of the surface pressure is a function of the zonda appearance in the plains. The dew point depression at $850 \mathrm{hPa}$ is important because the maximum dryness and heating due to zonda is found at that level. At that height the zonda may already be blowing in the morning of zonda days in the plains without having appeared on the surface yet.

Finally, a fourth set of predictors was obtained from Quintero rawinsonde (Chile) (Probabilistic Predictors PP4). In this case only three variables were rescued by SDA: zonal wind at $700 \mathrm{hPa}$ level, meridional wind at $250 \mathrm{hPa}$ level, and meridional wind component at $300 \mathrm{hPa}$ level. The proximity of a trough on zonda days implying a greater northern component (northwestern wind) would be the cause of the selection of the wind meridional components in the higher layers of the atmosphere windward of the Andes.

The "skill score" or "success degree" [29] was determined for each set of predictors. The first (PP1) had 0.40, the second (PP2) 0.38, the third (PP3) 0.47, and the fourth (PP4) only 0.21 .

\subsection{Model Forecasts}

Recently, some results of experiments trying to predict zonda wind have been obtained and presented in several workshops and conferences. In Santos et al. [30], a moderate event (FNZ1) registered at Mendoza Aero on May $27^{\text {th }}$, 2012, at 19 UTC was chosen to present GEM's capability in forecasting downslope windstorms. The model was initialized on May 25 ${ }^{\text {th }}$, 2012, almost three days before the event. This episode is shown in Figure 37(a) where zonda occurrence is characterized by a sudden increase of 10 degrees in surface temperature and a sudden decrease in dew point with an increase in the surface windfield.

Figure 37(b) shows the forecasted surface temperature, dew point and horizontal wind speeds, and Figure 37(c) shows the vertical time series of the simulated dew point depression. It can be seen there is good agreement between the forecast and the observation. It is worth noting that in some cases large horizontal winds and dry layers stay aloft and do not reach the surface ("high zonda wind" events).

In Santos et al. [31] the WRF and GEM models have been used to forecast zonda wind. The ability of each model to forecast this weather event has been estimated by computing statistical parameters such as bias (BIAS), standard deviation error (STDE) and the root mean square error (RMSE) (not shown). It can be inferred that WRF presents a better skill in forecasting surface temperature and dew point, but GEM seems to be slightly better in forecasting surface wind speed. As an example of a zonda forecast event, the time series of surface temperature, dew point and wind speed is shown for the severe summer event of December 24 ${ }^{\text {th }}$, 2012 (Figures 38(a)-(c)).

Actually the Eta/PRM model is run twice a day and is used to forecast zonda wind in many localities of central west Argentina leeward of the Andes with successful results. The Global Environmental Model (GEM) is also run daily, but it still needs some adjustments.

\subsection{Open Problems}

As in the European Alps, "the skills of experienced forecasters who are familiar with the local and regional situations are still an important pre-requisite for a successful forecast" [14]. The synoptic tools for predicting the onset of the zonda wind have been summarized in 7.1 and 7.2.

Probabilistic methods, recent models and their further improvements (in parameterization and in resolution) will improve zonda forecasting. An improved meteorological network with high density observations and more rawinsonde frequency is needed.

A high resolution model is necessary to answer typical questions such as when the zonda will start, where will it blow, for how long the episode is predicted, what the maximum gusts will be, among others.

\section{Societal Impact of Zonda}

\subsection{Climate Impact}

Zonda wind impacts on the local climate with more or less intensity depending on the season. When it blows in August or in September (when wintertime is coming to an end in Argentina) the wind strength and extreme dryness harm the agriculture, and the temperature rise can accelerate the blooming of fruit trees, which afterwards, 


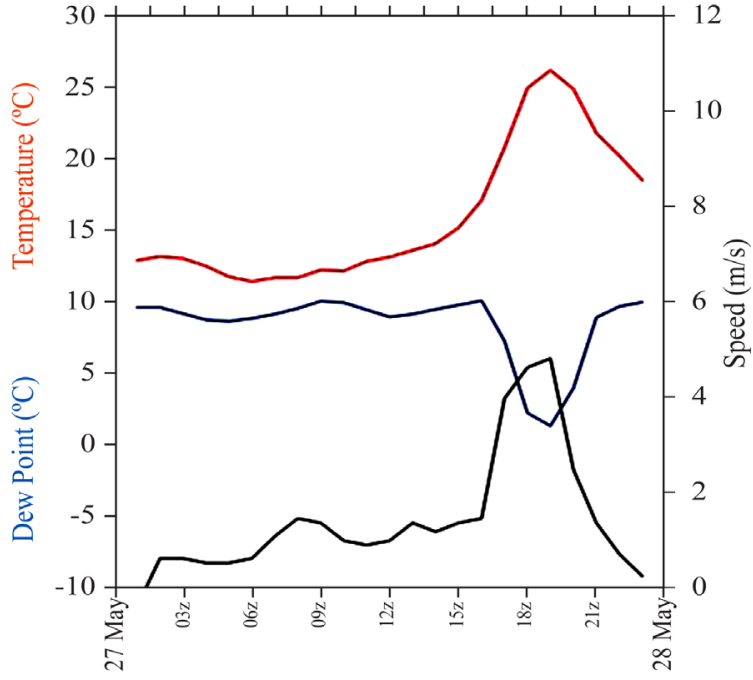

(a)

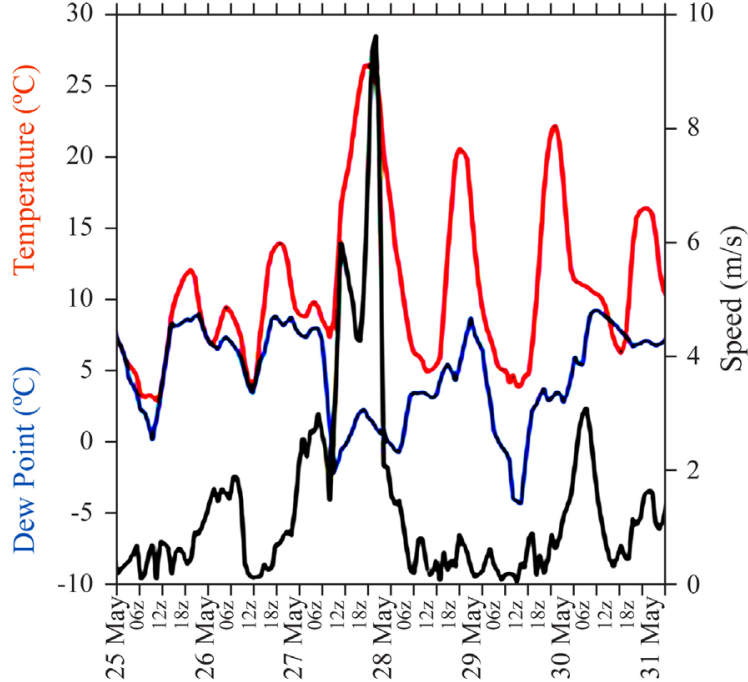

(b)

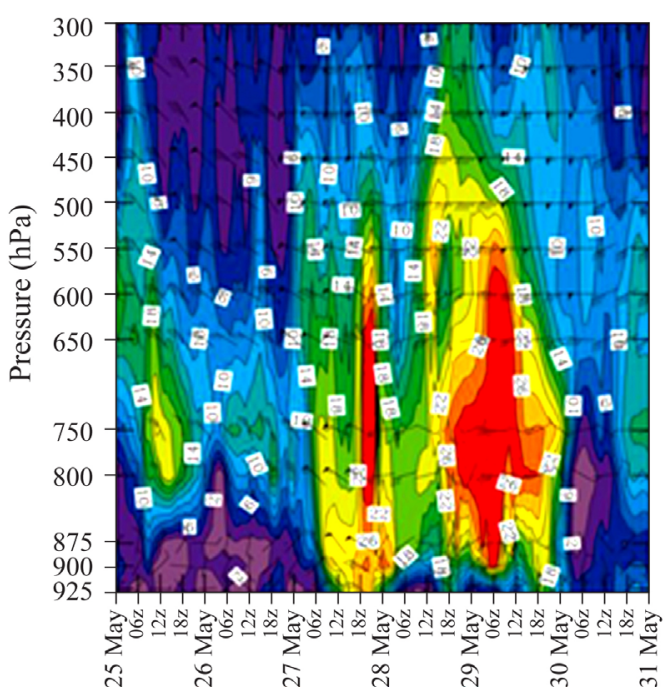

(c)

Figure 37. (a) Wind speed, temperature and dew point before, during and after de FNZ1 zonda event of May 27 ${ }^{\text {th }}$, 2012, on Mendoza Aero; (b) Forecasted surface parameters using GEM model for the zonda event of May 27 ${ }^{\text {th }}, 2012$, on Mendoza Aero.; (c) Forecasted dew point depression on the vertical axis using GEM model.

when the cold front arrives, are exposed to frost damage. In the high mountains the zonda speeds up the processes of fusion and evaporation of snow, modifies snow accumulation, contributes to the formation of avalanches, and influences the behavior of the hydrologic cycle.

\subsection{Air Quality}

The air quality under zonda conditions is quite variable. If the zonda is blowing in the upper levels and the cold pool is over Mendoza and/or San Juan cities (high zonda wind conditions), the thermal inversion maintains the haze and smog, and in few occasions, the fog.

When zonda wind reaches the surface, air quality depends on the season of the year. In fall and winter (particularly in August, the driest month of the year), dust and tree leaves affect the horizontal visibility.

Allende et al. [32] investigated the behavior of particulate matter over the Mendoza urban center during the zonda event of July $14^{\text {th }}$, 2011, and previous days, examining the role of meteorological fields over dust sources. 


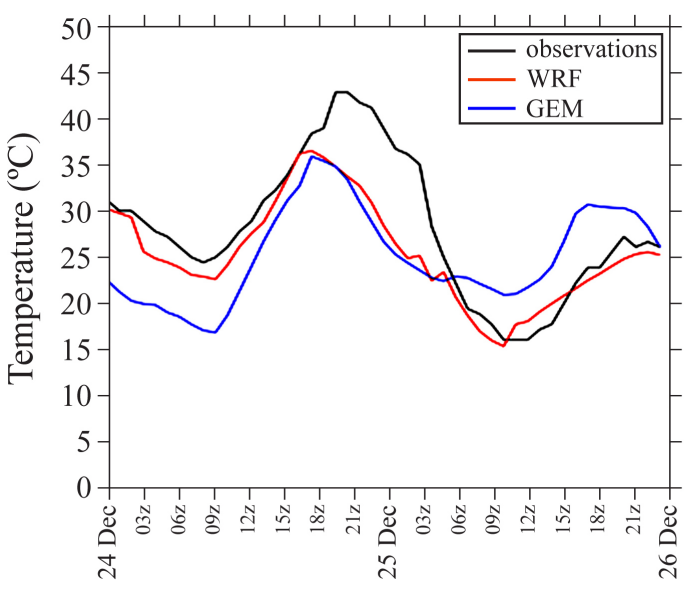

(a)

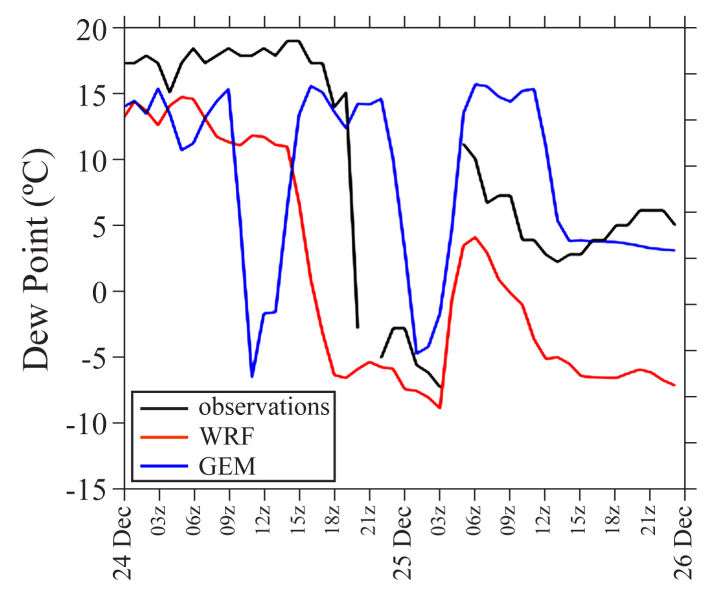

(b)

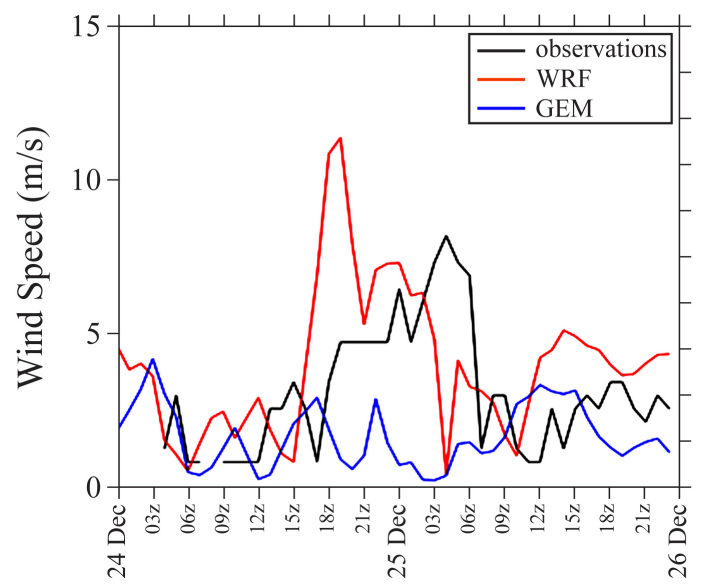

(c)

Figure 38. (a) Surface temperature; (b) Dew point; (c) Wind speed. All observed and forecasted by WRF and GEM models for the summer severe event of December $24^{\text {th }}$, 2012, for Mendoza Aero.

They used a regional coupled numerical weather prediction/dispersion, transport, and chemistry model to simulate the release and transport of soil dust (version 3.3 of Weather research and forecasting model with Chemistry; WRF/Chem [33]) and conclude that: "The model results showed that one dust plume is formed in the modelling domain originated in the northeast of the Mendoza province producing high dust concentrations in Eastern Mendoza with peaks up to $250 \mathrm{ug} / \mathrm{kg}$ air during the event. This allows making a preliminary assessment on the observed particulate matter concentrations over the urban centers.”

However, when zonda reaches the cities during spring, the wind is clean, with neither dust nor haze, and the sky has an intense blue color. On these occasions, just as in the Alps, the mountains can look "dark", and distant objects may seem much closer.

\subsection{Zonda Wind Damages}

In inhabited areas, the zonda wind produces different damages according to gust intensity: blown roofs, fallen trees and electricity cables, interrupted telephone and electric services, and fires (Figures 39(a)-(d)).

It is common to see the spread of many fires when zonda wind is blowing on the mountains close to Mendoza city. Sometimes this is a clear visual signal of the proximity of the phenomenon while it is still a "high zonda" event.

The main concern of the author, however, is not only the economic losses caused by this dreadful wind. The principal concern is the possible loss of human lives. A clear example of this is the fact that in the last earth- 

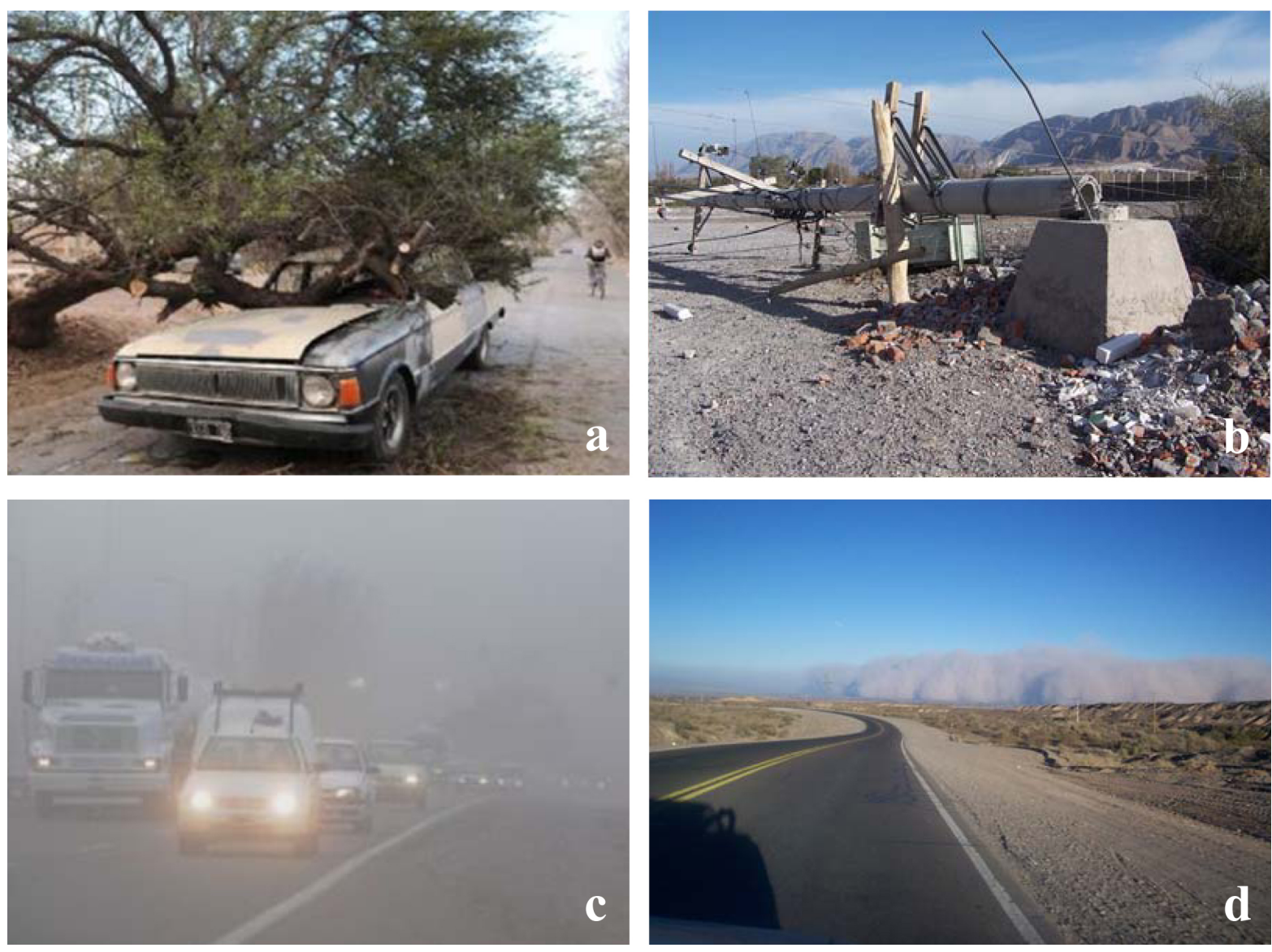

Figure 39. Impact of FNZ3 and FNZ4 event of July $11^{\text {th }}$, 2006: (a) Car damaged by a tree; (b) Electrical column destroyed; (c) Dust diminishing visibility; (d) Dust-storm over desert areas of San Juan province.

quake that affected Mendoza city on January $26^{\text {th }}$, 1985 , nine people died. In contrast, during the FNZ3 and FNZ4 episode of September $16^{\text {th }}$, 1992 , twenty two people died from the different effects caused by this very severe zonda windstorm.

Zonda winds are also dangerous to air traffic. High wind is very frequent over Mendoza and San Juan airports, and when the airplanes approach the land, the passengers feel the typical turbulence clearly. In the FNZ1 episode of May $27^{\text {th }}$, 2012, meteorology researchers flying to Mendoza to attend CONGREMET XI (Argentinian Meteorological Congress) failed to arrive on time. The pilot tried to land, but a sudden zonda gust prevented him, and he decided to return to Santiago de Chile.

\subsection{Biometeorological Effects}

Like foehn, chinook, northwestern Canterbury and other kinds of "foehn winds", zonda apparently has noticeable effects on the psychophysical state of the inhabitants, namely depression, lethargy, irritability, distress, and cardiac rhythm alteration, which in turn produce violent behavior and an increase in car accidents and heart attacks. It is worth noticing that these situations have been detected not only with surface-level zonda, but also during the previous days when a "high wind" zonda situation prevails.

As already mentioned, car accidents seem to be more frequent as people tend to be inattentive. Some explain this phenomenon saying that the cause is the de-ionization of the air. As in other parts of the world, like the European Alps, New Zealand Alps and the Rocky Mountains area of North America, in Andean regions people blame zonda winds for almost any ailment, accident, crime, and especially headaches.

At the beginning of the 1990s a group of the PRM (Regional Meteorology Program) started a research about the possible correlation between zonda and human health. The experience lasted a short time, and the only representative results were the daily admissions in the Neuropsychiatric Hospital of Mendoza city. During high 
zonda days and surface zonda days there was an increase in epilepsy and manic-depressive cases. However, there are no statistical analyses of pressure fluctuation or ion concentrations to establish any cause-effect mechanism. Chiconi [20] showed that $62.86 \%$ of the equine colic analyzed was observed when there was a high zonda day or zonda wind on the surface or when a cold front without significant evidence of zonda effect was simply getting closer.

\section{Discussion and Conclusion}

The state-of-the-art research on the zonda wind in South America analyzed in this paper allows us to conclude that there has been substantial progress in the understanding of this kind of complex wind during the last years, especially since the last decade. This progress has been accelerated by the use of different models. This paper has highlighted some of these advances by synthesizing some of the major findings.

The probabilistic prediction method developed towards the end of the $20^{\text {th }}$ century is still very useful to predict the occurrence of this phenomenon in the cities of San Juan and Mendoza. This as well as the new available tools, such as the Eta/PRM and GEM models running operatively (continuously) at PRM (Programa Regional de Meteorología), offered the community the possibility to generate an Early Warning System to warn the population about the adverse and dangerous effects of this phenomenon, particularly in its severe manifestations.

In 2014 the Mendoza Congress passed a Law approved unanimously to develop a "procedure for the operative management of extreme regional meteorological phenomena" [34], Currently, this Law is under regulatory process. However, as mentioned in point 7.5, it is necessary to adjust the available models to work with better resolutions to meet the demands of decision-makers and the population at large.

The answer to questions regarding time of onset of the event, place where it will occur first, parts of the territory it will affect, duration, intensity and offset, still poses a big challenge for researchers and forecasters in the region. Like in other parts of the world with a similar phenomenon, there is a lack of research knowledge regarding the biometeorological aspects of zonda. An interdisciplinary research project which links this wind with its potential impact on human health is a pending key issue.

\section{Acknowledgements}

The author wishes to thank Silvia Simonelli, Rubén Santos, Federico Otero, Diego Araneo, Julio Cristaldo and Martín Silva for their essential collaboration. Special thanks to Rafael Bottero for his help with figures and photos, to Silvia Barbuzza for her linguistic validation, and to Claudia Bottero for formatting and proofreading.

This paper has been funded by PIP 1120090100439 of CONICET (National Research Council of Argentina).

\section{References}

[1] Norte, F. (1988) Características del Viento Zonda en la Región de Cuyo. PhD Thesis, University of Buenos Aires, 255 pp. Available from Programa Regional de Meteorología (PRM), Instituto Argentino de Nivología, Glaciología y Ciencias Ambientales. (IANIGLA), Centro Científico Tecnológico (CCT), CONICET, Mendoza, Argentina. (In Spanish) http://www.prmarg.org/tesis-doctorado

[2] Norte, F., Ulke, A., Simonelli, S. and Viale, M. (2008) The Severe Zonda Wind Event of 11 July 2006 East of the Andes Cordillera (Argentine): A Case Study Using The BRAMS Model. Meteorology and Atmospheric Physics, 102, 1-14. http://dx.doi.org/10.1007/s00703-008-0011-6

[3] Huschke, R.E. (Ed.) (1980) Glossary of Meteorology. American Meteorological Society, Boston, 638 p.

[4] Mesinger, F., Jovic, D., Chou, S.C., Gomes, J.L. and Bustamante, J.F. (2006) Wind Forecast around the Andes using the Sloping Discretization of the Eta Coordinate. Proceedings of the 8th International Conference on the Southern Hemisphere Meteorology and Oceanography, Foz do Iguaçu, 24-28 April 2006, 1837-1848.

[5] Brinkmann, W.A.R. (1974) Strong Downslope Winds at Boulder, Colorado. Monthly Weather Review, 102, $592-602$. http://dx.doi.org/10.1175/1520-0493(1974)102<0592:SDWABC>2.0.CO;2

[6] Lamb, P. (1974) Norwesters Potential Foehn Influence on Canterbury Plains (New Zealand) Surface Heat Exchanges. New Zealand Journal of Agricultural Research, 17, 349-355. http://dx.doi.org/10.1080/00288233.1974.10430566

[7] Lindesay, J.A. (1990) Thermo-Orographically Boundary Layer Oscillations over the Central Namibia, Southern Africa. International Journal of Climatology, 10, 63-77. http://dx.doi.org/10.1002/joc.3370100108

[8] Kalnay, E., Kanamitsu, M., Kistler, R., Collins, W., Deaven, L., Gandin, L., Iredell, M., Saha, S., Woolen, J., Zhu, Y., Chelliah. M., Ebizuzaki, W., Higgins, W., Janowiak, J., Mo, K., Ropelevski, C., Wang, J., Leetmaa, A., Reynolds, R., 
Roy, J. and Dennis, J. (1996) The NCEP/NCAR 40-Year Reanalysis Project. Bull Am Meteorol Soc, 77, 437-471. http://dx.doi.org/10.1175/1520-0477(1996)077<0437:TNYRP>2.0.CO;2

[9] Otero, F. and Norte, F. (2014) Statistical Analysis and Classification Methods for Zonda Wind in San Juan City, Argentina. XXVII Conferencia de la Asociación Argentina de Geofísicos y Geodestas (AAGG), November 2014, San Juan. (In CD)

[10] Seluchi, M.E., Norte, F.A., Satyamurty, P. and Chou, S.C. (2003) Analysis of Three Situations of the Foehn Effect over the Andes (Zonda Wind) Using the Eta-CPTEC Regional Model. Weather Forecast, 18, 481-501. http://dx.doi.org/10.1175/1520-0434(2003)18<481:AOTSOT>2.0.CO;2

[11] Norte, F., Seluchi, M., Gomes, J. and Simonelli, S. (2007) Análisis de una Ola de Calor Extrema en la Región Subtropical de América del Sur. Revista Brasileira de Meteorologia, 22, 373-386. (In Spanish) http://dx.doi.org/10.1590/S0102-77862007000300010

[12] Cotton, W.R., Pielke, R.A., Walko, R.L., Liston, G.E., Tremback, C.J., Jiang. H., McAnelly, R.L., Harrington, J.Y., Nicholls, M.E., Carrió, G. and MacFadden, J.P (2003) RAMS 2001: Current Status and Future Directions. Meteorology and Atmospheric Physics, 82, 5-29. http://dx.doi.org/10.1007/s00703-001-0584-9

[13] Ulke, A.G., Saulo, A.C. and Nicolini, M. (2001) Simulación con el modelo de mesoescala RAMS de las Condiciones Asociadas a la Ocurrencia de un Mesosistema Convectivo. In: Proceedings of the IX Congreso Latinoamericano e Ibérico de Meteorología-VIII Congreso Argentino de Meteorología, No. 261, 10 pp. (In Spanish)

[14] Richner, H. and Hächler, P. (2013) Understanding and Forecasting Alpine Foehn. In: Chow, F.K., De Wekker, S.F.J. and Snyder, B.J., Eds., Mountain Weather Research and Forecasting, Springer Atmospheric Sciences, 219-260 (Chapter 4). http://dx.doi.org/10.1007/978-94-007-4098-3_4

[15] Georgii, W. (1952) Regulación del tiempo por la doble onda diaria de la presión atmosférica en Mendoza. Meteoros, II, 182-189.

[16] Georgii, W. (1954) Dinámica del viento Zonda en Mendoza. In: Anales del Departamento de Investigaciones Científicas de la Universidad Nacional de Cuyo, UNCU Editors, Mendoza, 109-119.

[17] Rolón de los Santos, G. and Afonso, J. (1977) Aspectos estadísticos y sinópticos del viento Zonda. Meteorológica, VIII/IX, 321-330.

[18] Lichtenstein, E.R. (1980) La Depresión del Noroeste Argentino. PhD Thesis, Facultad de Ciencias Exactas y Naturales. Universidad de Buenos Aires, Buenos Aires.

[19] Viale, M. and Norte, F. (2009) Strong Cross-Barrier Flow under Stable Conditions Producing Intense Winter Orographic Precipitation: A Case Study over Subtropical Central Andes. Weather and Forecasting, 24, 1009-1031. http://dx.doi.org/10.1175/2009WAF2222168.1

[20] Chiconi, S. (2010) Estudio Retrospectivo de la Influencia del Viento Zonda y otros Factores Meteorológicos en el Cólico Equino en el Cuerpo de la Policía Montada de la Policía de la Provincia de Mendoza. Undergraduate Thesis, Facultad de Ciencias Veterinarias y Ambientales, Universidad Juan Agustin Maza, Mendoza.

[21] Palese, C. and Cogliati, M.G. (2014) Detección de Casos de Viento Zonda Norpatagónico. XXVII Reunión Científica de la Asociación Argentina de Geofísicos y Geodestas, San Juan, November 2014. (Sent to GEOACTA to be published, in revisión)

[22] Otero F., Norte, F. and Araneo, D. (2015) Obtención de un Índice de Probabilidad de Viento Zonda en Mendoza mediante el Análisis de Componentes Principales IANIGLA-CCT-CONICET-Mendoza. (Accepted for CONGREMET XII, Mar del Plata, 26-29 May 2015)

[23] Yuchechen, A., Norte, F. and Araneo, D. (2015) Comparación de Estructuras Verticales de Temperatura y Humedad entre Condiciones Normales y Eventos Zonda para Distintas Localidades del Cono Sur de Sudamérica. (Accepted for CONGREMET XII, Mar del Plata, 26-29 May 2015)

[24] Brinkmann, W.A.R. (1973) A Climatological Study of Strong Downslope Winds in the Boulder Area. PhD Thesis, NCAR (Natural Center for Atmospheric Research), Boulder, Colorado.

[25] Ferreira, L.J. (2008) Causas y Variabilidad de la Depresión del Noroeste Argentino e Impactos sobre los Patrones Regionales de Circulación. PhD Thesis, University of Buenos Aires, Buenos Aires, 177 pp. (In Spanish)

[26] Steinacker, R. (2006) Alpine Foehn-A New Verse to an Old Song. Promet, 32, 3-10. (In German)

[27] Silva, A.R. (2004) Ondas Orográficas sobre a Cordilheira dos Andes em Latitudes Subtropicais: Estudo de Caso. MSc Thesis, São José dos Campos, 114 pp. (INPE-10528-TDI/935)

[28] Norte, F., Santos, J.R., Hofer J.A., Araneo, D.A. and Simonelli, S.C. (2014) Zonda Wind Events: When Do They Arrive to the Metropolitan Area of Mendoza? WCRP Conference for Latin America and the Caribbean: Developing, Linking and Applying Climate Knowledge, Montevideo, 17-21 March 2014. (Poster Session)

[29] Brier, G.W. (1950) Verification of Forecasts Expressed in Terms of Probability. Monthly Weather Review, 78, 1-3. 
http://dx.doi.org/10.1175/1520-0493(1950)078<0001:VOFEIT>2.0.CO;2

[30] Santos, J.R., Norte, F., Nagarajan, B., Araneo, D.A., Simonelli, S.C. and Bustos, C. (2014) Forecasting and Nowcasting of Severe Weather. Seventh European Conference on Severe Storms (ECSS), 3-7 June 2013, Helsinki. (Poster Session)

[31] Santos, J.R., Hofer, J.A., Norte, F., Araneo, D.A. and Simonelli, S.C. (2014) Choosing a Numerical Weather Prediction Model to Forecast Zonda Wind. WCRP Conference for Latin America and the Caribbean: Developing, Linking and Applying Climate Knowledge, 17-21 March 2014, Montevideo, Uruguay. (Poster Session)

[32] Allende, D.G., Mulena, G.C., Puliafito, S.E., Lakkis, S.G., Cremades, P.G. and Castro, F.H. (2012) A first approach on modeling windblown dust in Zonda wind events. In: XI Congreso Argentino de Meteorología (CONGREMET XI), Mendoza, 28 May-1 June 2012.

[33] Grell, G.A. (2005) Fully Coupled Online Chemistry within the WRF Model. Atmospheric Environment, 39, $6957-6975$. http://dx.doi.org/10.1016/j.atmosenv.2005.04.027

[34] INFOJUS (2014) Creación del Procedimiento para el manejo operativo de fenómenos meteorológicos extremos regionales. LEY 8692. Boletín Oficial, Mendoza. Id Infojus: LPM 0008692. Sistema Argentino de Información Jurídica (Argentine System of Juridical Information). www.infojus.gob.ar 